\title{
Mitochondria-targeting graphene oxide nanocomposites for fluorescence imaging-guided synergistic phototherapy of drug-resistant osteosarcoma
}

\author{
Wei-Nan Zeng ${ }^{1,2}$, Qiu-Ping Yư ${ }^{3}$, Duan Wang ${ }^{1}$, Jun-Li Liu², Qing-Jun Yang ${ }^{2^{*}}$, Zong-Ke Zhou ${ }^{1 *}$ and Yi-Ping Zeng ${ }^{2^{*}}$ (D)
}

\begin{abstract}
Background: Osteosarcoma (OS) is the most common primary malignant bone tumor occurring in children and young adults. Drug-resistant osteosarcoma often results in chemotherapy failure. Therefore, new treatments aimed at novel therapeutic targets are urgently needed for the treatment of drug-resistant osteosarcoma. Mitochondriatargeted phototherapy, i.e., synergistic photodynamic/photothermal therapy, has emerged as a highly promising strategy for treating drug-resistant tumors. This study proposed a new nano-drug delivery system based on nearinfrared imaging and multifunctional graphene, which can target mitochondria and show synergistic phototherapy, with preferential accumulation in tumors.
\end{abstract}

Methods and results: Based on our previous study, (4-carboxybutyl) triphenyl phosphonium bromide (TPP), a mitochondria-targeting ligand, was conjugated to indocyanine green (ICG)-loaded, polyethylenimine-modified PEGylated nanographene oxide sheets (TPP-PPG@ICG) to promote mitochondrial accumulation after cellular internalization. Thereafter, exposure to a single dose of near-infrared irradiation enabled synergistic photodynamic and photothermal therapy, which simultaneously inhibited adenosine triphosphate synthesis and mitochondrial function. Induction of intrinsic apoptosis assisted in surmounting drug resistance and caused tumor cell death. After fluorescence imagingguided synergistic phototherapy, the mitochondria-targeting, multifunctional graphene-based, drug-delivery system showed highly selective anticancer efficiency in vitro and in vivo, resulting in marked inhibition of tumor progression without noticeable toxicity in mice bearing doxorubicin-resistant MG63 tumor cells.

Conclusion: The mitochondria-targeting TPP-PPG@ICG nanocomposite constitutes a new class of nanomedicine for fluorescence imaging-guided synergistic phototherapy and shows promise for treating drug-resistant osteosarcoma.

Keywords: Synergistic phototherapy, Mitochondria-targeting, Drug-resistant osteosarcoma, Graphene oxide, Singlelaser activation

*Correspondence: qingjunyang_cgh@163.com; zongkehx@163.com; zyp860625@126.com

1 Department of Orthopedics, West China Hospital/West China School of Medicine, Sichuan University, Chengdu 610041, China

2 Department of Orthopedics, Chongqing General Hospital, University of Chinese Academy of Sciences, Chongqing 400014, China

Full list of author information is available at the end of the article

\section{Introduction}

Osteosarcoma (OS) is the most common primary malignant bone tumor occurring in children and young adults. Currently, the gold standard for OS treatment consists of polychemotherapy, followed by radical excision of tumor and metastases, and subsequent polychemotherapy. The 5 -year survival rate is $70 \%$ in patients with nonmetastatic disease or $\sim 20 \%$ in patients with metastatic

c) The Author(s) 2021. This article is licensed under a Creative Commons Attribution 4.0 International License, which permits use, sharing, adaptation, distribution and reproduction in any medium or format, as long as you give appropriate credit to the original author(s) and the source, provide a link to the Creative Commons licence, and indicate if changes were made. The images or other third party material in this article are included in the article's Creative Commons licence, unless indicated otherwise in a credit line to the material. If material is not included in the article's Creative Commons licence and your intended use is not permitted by statutory regulation or exceeds the permitted use, you will need to obtain permission directly from the copyright holder. To view a copy of this licence, visit http://creativeco mmons.org/licenses/by/4.0/. The Creative Commons Public Domain Dedication waiver (http://creativecommons.org/publicdomain/ zero/1.0/) applies to the data made available in this article, unless otherwise stated in a credit line to the data. 
or recurrent disease [1, 2]. Unfortunately, this treatment achieves disease control in $\leq 60 \%$ of patients with OS. Moreover, the prognosis of OS has not improved in recent decades $[3,4]$. Drug resistance represents the major limitation of current therapies. Such resistance arises from overexpression of adenosine triphosphate (ATP)-binding cassette transporters, such as P-glycoprotein $(\mathrm{P}-\mathrm{gP})$, which expulses anticancer drugs and the selection for drug-resistant cell clones after treatment [5]. These drug-resistant clones can ultimately lead to tumor recurrence or metastatic progression [6]. Therefore, new treatments aimed at novel therapeutic targets are urgently needed.

Recently, mitochondria have received extensive attention as effective targets for tumor treatment. Mitochondria play vital roles in various biological processes, such as initiation of the intrinsic-apoptosis pathway [7-9]. Mitochondrial alterations are hallmarks of oncogenesis, tumor progression, angiogenesis, and chemotherapeutic resistance [10]. During mitochondrial apoptosis, cytochrome $\mathrm{c}$ is released from the mitochondria, which subsequently activates the caspase cascade. Hence, targeting mitochondria holds tremendous therapeutic potential for eradicating cancer [10-13].

Synergistic phototherapy, represented by photodynamic therapy (PDT) and photothermal therapy (PTT), can be used to treat drug-resistant tumors with better treatment outcomes than chemotherapy. Synergistic phototherapy is a non-invasive, highly selective, and effective approach with low systemic toxicity for cancer treatment [14]. In phototherapy, light is administered, absorbed by a photosensitizer (PS) or photothermal agent, and converted into reactive oxygen species (ROS) or local hyperthermia, leading to tumor cell death [15]. The rational combination of PDT and PTT may synergistically improve therapeutic outcomes and efficacies for cancer treatment [16]. However, due to spectral mismatches between PDT and PTT agents in the near-infrared (NIR) region, sequential irradiations by two different lasers are required to activate both PDT and PTT, which complicates the treatment process and prolongs the treatment time. In addition, it is difficult to precisely align two laser beams at the same position. Furthermore, some intrinsic barriers such as a short lifetime (10-320 ns) and limited diffusion radius $(10-55 \mathrm{~nm})$ of ROS decrease the therapeutic outcome of PDT [17]. Thus, using a single NIR laser to activate synergistic phototherapy offers promise for generating ROS in cellular organelles that are vulnerable to ROS.

Among the cellular organelles, the mitochondrion is the most sensitive to ROS and hyperthermia-mediated damages that can rapidly perturb mitochondrial functions, change the mitochondrial membrane potential, reduce ATP production, and induce tumor cell apoptosis [18-21]. Thus, selective generation of ROS and hyperthermia via phototherapy in the mitochondria may considerably improve their therapeutic efficacy. Furthermore, combined hyperthermia and suppressed ATP production due to ROS-mediated mitochondrial dysfunction could be another effective strategy for surmounting drug resistance [12]. Therefore, mitochondria-targeted synergistic phototherapy may serve as an alternative strategy in drug-resistant OS therapy.

Thus, selectively and efficiently enhancing the mitochondrial accumulation of PS and photothermal agents, which can be efficiently and simultaneously triggered by a single NIR laser that is accurately focused on tumor regions, and sufficiently converting the optical energy to ROS and hyperthermia, are vitally important. Hence, during phototherapy, it is necessary to outline the tumor margin in real-time to demarcate it from the normal tissue and focus the laser beam accurately on the tumor regions. Fluorescence (FL) imaging in the NIR region (700-900 nm) can be used to monitor in real-time the dynamic distribution of PS and photothermal agents in vivo, and to detect tumors and tumor margins [22]. Furthermore, to enhance the treatment efficiency, reduce the number of operation steps and the treatment time, and completely use the synergistic effect of PDT and PTT, the PS and the photothermal agents must simultaneously delivered to mitochondria as composite nanostructures and triggered using a single NIR laser [23, 24]. However, synergistic phototherapy with a single laser strongly depends on overlap between the optical absorption spectra of the PS and photothermal agents. This special requirement and complex synthesis processes may limit their combined use. However, a great demand exists for developing simple, yet highly effective nanocomposites to coordinate PTT with PDT.

Indocyanine green (ICG), the only NIR contrast agent approved by the FDA for clinical use, can not only be used for NIR FL imaging, but can also convert optical energy to ROS and local hyperthermia for synergistic phototherapy [25]. Thus, ICG can be considered an ideal theranostic platform for tumor treatment [26]. However, several disadvantages have prevented the application of ICG in tumor theranostics, including: (i) short half-life in the circulation; (ii) poor photo-stability; (iii) the possibility of unidirectional expulsion by P-gP; (iv) the lack of cancer-specific accumulation for targeted treatment; (v) concentration-dependent aggregation, and (vi) limited efficacy in cancer phototherapy and the need to combine it with other treatments to improve therapeutic outcomes [27]. Hence, we designed a new nanocomposite based on a polyethylenimine-modified PEGylated nanographene oxide (PPG), as we described previously [28-31]. NGO 
is a planar nanomaterial with an extremely high loading capacity for therapeutic agents, high cellular uptake, and a good photothermal effect, which can enhance the phototherapy of ICG. Furthermore, graphene oxide and ICG can be optimally excited with a single-wavelength NIR laser at $808 \mathrm{~nm}$, which is also suitable for NGO for PTT. Functionalization with polyethylene glycol (PEG), referred to hereafter as GO-PEG, exhibited high delivery efficiency and the controllable release of proteins, gene medicines, bioimaging agents, chemotherapeutics, and anticancer drugs. GO-PEG has a good biological safety profile and causes no significant side effects in vitro or in vivo; in addition, it can be gradually excreted over time [32-34]. Besides, cationic polymer polyethyleneimine (PEI)-modified GO showing excellent stability in physiological solutions and electropositivity which may promote nanocomposite intracellular delivery [35]. Otherwise, the amido functional groups of PEI located at the edge of PPG are abundant for further functionalization. Subsequently, (4-Carboxybutyl) triphenyl phosphonium bromide (TPP), a mitochondria-targeting ligand, was conjugated with PPG via covalent interaction between the amido functional groups of PEI and the carboxy group of TPP to yield the TPP-PPG@ICG nanocomposite $[11,36]$. After intravenous administration, the resulting nanocomposite accumulated in tumors due to the enhanced-permeability-and-retention (EPR) effect, targeted the mitochondria, and killed cancer cells via phototherapy in situ upon laser irradiation. Ultimately, this led to robust antitumor efficacy with reduced systemic adverse effects (Scheme 1).

\section{Materials and methods Materials}

TPP ((4-Carboxybutyl)triphenyl phosphonium bromide), $\quad \mathrm{NaN}_{3}, \quad N$-(3-dimethylamino propyl- $N^{\prime}-$ ethylcarbodiimide) hydrochloride (EDC. $\mathrm{HCl})$, and $N$-hydroxysuccinimide (NHS) were obtained from Sigma-Aldrich (Saint Louis, MO, USA). FBS, penicillin-streptomycin, and trypsin were purchased from Gibco (Grand Island, NY, USA). The ROS Kit (containing DCFH-DA), singlet oxygen sensor green (SOSG), MitoTracker, MitoSOX Red, calcein AM, Propidium iodide (PI), and the J-aggregate-forming lipophilic cation (JC-1) were purchased from Molecular Probes (Eugene, OR, USA). The ATP Determination kit (A22066) and cell lysis buffer $(16,189)$ were purchased from Invitrogen (Carlsbad, CA, USA). DMEM medium was purchased from HyClone (Logan, UT, USA). Matrigel and the Annexin V-FITC Apoptosis Detection Kit were purchased from BD Biosciences (San Diego, CA, USA). ICG and the Cell Counting Kit-8 (CCK-8) were purchased from Dojindo (Kumamoto, Japan). Dialysis ultrafiltration tubes and bags with a $10-\mathrm{kDa}$ molecular weight cutoff were purchased from Millipore, Inc. (Billerica, MA, USA). All chemicals and reagents were of analytical grade.

\section{Cells, animals, and tumor xenografts}

The human OS cell line MG63 and the doxorubicinresistant OS cell line (MG63/Dox) were purchased from the American Type Culture Collection (USA). Both cell lines were grown as monolayers in DMEM medium supplemented with $10 \%$ FBS and $1 \%$ penicillin-streptomycin at $37^{\circ} \mathrm{C}$ in a $5 \% \mathrm{CO}_{2}$ humidified atmosphere.

Athymic male nude mice (aged 6 weeks, weighing 18-22 g) were obtained from the Laboratory Animal Center of the Chongqing General Hospital (Chongqing, China) and were housed in individual vented cages under specific pathogen-free conditions with a $12 \mathrm{~h}$ day/12 h night cycle; food and water were provided ad libitum. All animal protocols were reviewed and approved by the Institutional Animal Care and Use Committee of the Chongqing General Hospital. MG63/Dox cells (approximately $1 \times 10^{7}$ ) were resuspended in $100 \mu \mathrm{L}$ Matrigel and subcutaneously implanted into the right flanks of different mice. Tumor-bearing mice were used for in vivo imaging and for phototherapy when the tumor volume reached $60 \mathrm{~mm}^{3}$.

\section{Synthesis of NGO-PEG-BPEI (PPG), TPP-PPG and TPP-PPG@ ICG}

NGO was prepared according to the modified-Hummer's method, starting with the oxidization of graphite sheets, followed by ultrasonication [37]. NGO-PEG (PG) and the NGO-PEG-BPEI (PPG) were prepared according to our previously described method [28-31]. To conjugate TPP with PPG, $5 \mathrm{mg}$ of TPP was dissolved in $4 \mathrm{~mL}$ water and activated using EDC. $\mathrm{HCl}(15 \mathrm{mg})$ and NHS $(15 \mathrm{mg})$ for $15 \mathrm{~min}$ at room temperature. Subsequently, $4 \mathrm{~mL}$ of PPG $(1.0 \mathrm{mg} / \mathrm{mL})$ solution was added to the reaction mixture and magnetically stirred at room temperature for $24 \mathrm{~h}$. Finally, excess TPP was removed via filtration through a $10-\mathrm{kDa}$ filter (Millipore, Inc.) and washed repeatedly with double-distilled water to obtain PPG-TPP (NGO-PEG equivalent, $0.5 \mathrm{mg} / \mathrm{mL}$ ).

To synthesize TPP-PPG@ICG, ICG (7.74 mg) was dissolved in $1 \mathrm{~mL}$ of anhydrous dimethyl sulfoxide as a stock solution $(10 \mathrm{mM})$ for further use. Two hundred microliters of ICG $(10 \mathrm{mM})$ and $1.8 \mathrm{~mL}$ of TPP-PPG $(0.5 \mathrm{mg} /$ $\mathrm{mL}$ ) were mixed and stirred for $24 \mathrm{~h}$ at room temperature. Then, the whole system was dialyzed against distilled water for $24 \mathrm{~h}$ (molecular weight cut-off: $10 \mathrm{kDa}$ ). The final product (TPP-PPG@ICG) was freeze-dried and stored below $4{ }^{\circ} \mathrm{C}$ for further use. 


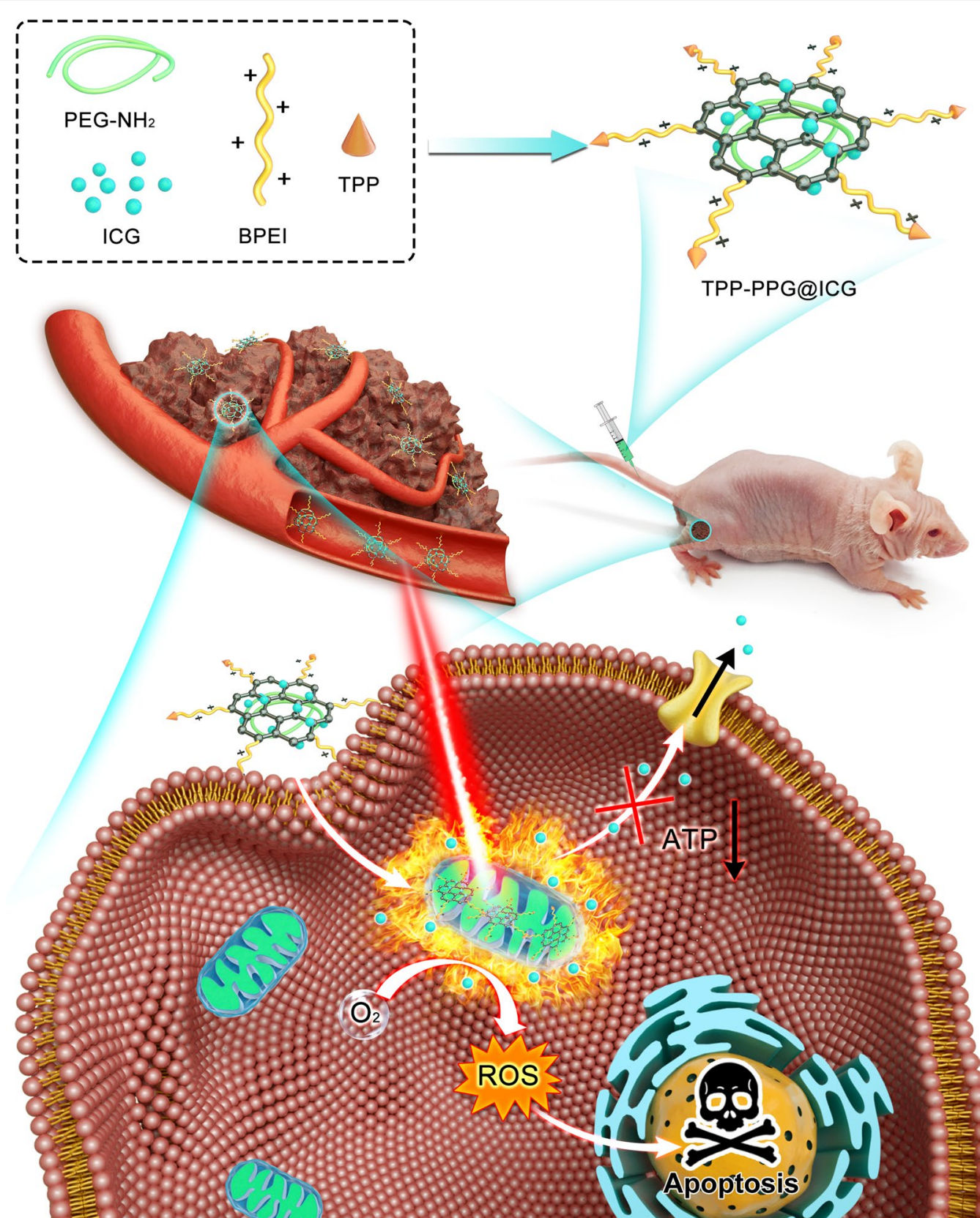

Scheme 1. Schematic illustration showing a TPP-PPG@ICG nanocomposite targeting a mitochondrion for synergistic phototherapy with a single laser. The PS agent (ICG) was grafted onto the PEG- and BPEl-functionalized photothermal agent (NGO) to obtain TPP-PPG@ICG. After cellular internalization, TPP-PPG@ICG accumulated in mitochondria, induced mitochondria-related intrinsic apoptosis, surmounted drug resistance, and enhanced the antitumor efficacy after laser irradiation at $808 \mathrm{~nm}$

\section{Characterization}

Fourier transform infrared spectroscopy (FT-IR) spectra were obtained for TPP-PPG@ICG using a Nicolet 6700 spectrometer (Thermo Scientific) to confirm that ICG was loaded onto the NGO. An atomic force microscope (AFM) instrument (Bruker Dimension Icon) was used to characterize the size and thickness of TPPPPG@ICG. The optical properties of TPP-PPG, ICG, and TPP-PPG@ICG were characterized using an Ultraviolet-visible-infrared (UV-vis-NIR) spectrometer in 50\% isopropyl alcohol (UV-3600 Scanning Spectrophotometer, Shimadzu, Japan). The hydrodynamic size of TPP-PPG and TPP-PPG@ICG in water were tested 
by DLS using a ZetaPALS analyzer (Brookhaven Instruments, Holtsville, NY, USA).

Nanoparticle stability was tested as follows: TPP-PPG or TPP-PPG@ICG was incubated with PBS, DMEM medium, or PBS $+10 \%$ fetal bovine serum (FBS), and the mixtures were monitored for the appearance of precipitates after direct centrifugation at $5000 \mathrm{rpm} \mathrm{min}{ }^{-1}$ for $10 \mathrm{~min}$. Additionally, the TPP-PPG@ICG were incubated with PBS and PBS $+10 \%$ FBS for 0, 4, 12 and $24 \mathrm{~h}$, then the stability of nanoparticles was tested by DLS using a ZetaPALS analyzer (Brookhaven Instruments, Holtsville, NY, USA).

The release of ICG from TPP-PPG@ICG was studied by adding the material to acidic $(\mathrm{pH}=5.0)$ or alkalescent $(\mathrm{pH}=7.4) \mathrm{PBS}$ at $37{ }^{\circ} \mathrm{C}$ or $43{ }^{\circ} \mathrm{C}$, respectively. To determine the release kinetics of ICG from TPP-PPG@ ICG, PBS was collected after centrifugation and replaced with the same volume of PBS at each sampling time. The amounts of ICG released from TPP-PPG were evaluated using a UV-vis-NIR spectrometer for loadingefficiency measurements. To determine the ICG loading on TPP-PPG, TPP-PPG@ICG solution was diluted in $5 \mathrm{~mL}$ ethyl acetate/ethanol $(9: 1, \mathrm{v} / \mathrm{v})$ and sonicated for $30 \mathrm{~min}$ to completely release ICG. ICG levels were determined by measuring the UV-vis-NIR absorption spectra. ICG loading was defined as follows: ICG content $(\%, w / w)=(I C G$ weight in TPP-PPG@ICG/TPP-PPG weight $) \times 100 \%$. All the measurements were performed in triplicate.

\section{Single oxygen detection}

The generation of singlet oxygen $\left({ }^{1} \mathrm{O}_{2}\right)$ was evaluated using SOSG. Typically, solutions containing ICG, TPPPPG, and TPP-PPG@ICG (ICG concentration =10 $\mu \mathrm{M}$ ) were mixed with SOSG, which was dissolved in water containing $2 \%$ methanol to a final concentration of $1 \mathrm{mM}$. Then, the mixture was immediately irradiated with a laser at $808 \mathrm{~nm}$ for $5 \mathrm{~min}$ (energy density: $0.6 \mathrm{~W} / \mathrm{cm}^{2}$ ). The emission peak of SOSG at $530 \mathrm{~nm}$ was obtained by excitation with a light source at $494 \mathrm{~nm}$, and the data were quantified for singlet oxygen generation.

\section{Measurements of photothermal performance}

One milliliter each of PBS, ICG, TPP-PPG, and TPPPPG@ICG in aqueous solution was placed in a quartz cell and irradiated at $808 \mathrm{~nm}$ with a power density of $0.6 \mathrm{~W} /$ $\mathrm{cm}^{2}$ for $10 \mathrm{~min}$ at pre-designed time intervals $(0 \mathrm{~min}$, $2.5 \mathrm{~min}, 5.0 \mathrm{~min}, 7.5 \mathrm{~min}$, and $10.0 \mathrm{~min}$ ). The temperature was measured using an infrared thermometer.

\section{Cellular uptake and intracellular localization}

MG63/Dox cells were seeded in 6-well plates at a density of $1 \times 10^{5}$ cells/well. After overnight incubation,
TPP-PPG@ICG was added at a final concentration of $10 \mu \mathrm{M}$. After $1 \mathrm{~h}, 4 \mathrm{~h}, 8 \mathrm{~h}, 12 \mathrm{~h}$, or $24 \mathrm{~h}$ of incubation, the cells were washed thrice with PBS, trypsinized, resuspended in medium, and harvested for analysis using flow cytometry using a FACSVerse instrument (BD Biosciences). The mean FL intensity of $1 \times 10^{4}$ cells was recorded for each sample.

To study subcellular localization, MG63/Dox cells $\left(1 \times 10^{5}\right.$ cells per $\left.\mathrm{mL}\right)$ were exposed to TPP-PPG@ICG (ICG concentration $=10 \mu \mathrm{M}$ ) on $35-\mathrm{mm}$ glass-bottom dishes for $24 \mathrm{~h}$. After rinsing thrice with PBS, the cells were treated with MitoTracker for $10 \mathrm{~min}$ to stain the mitochondria. Then, the cells were washed thrice with PBS before capturing images using a confocal laser-scanning microscope (CLSM).

\section{In vitro analysis}

MG63/Dox cells were seeded in 96-well plates $\left(5 \times 10^{3}\right.$ cells/well in $\left.100 \mu \mathrm{L}\right)$ and incubated for $24 \mathrm{~h}$. Then, ICG, TPP-PPG, PPG@ICG, or TPP-PPG@ICG was added to various concentrations of ICG. Subsequently, the cells in the non-irradiated groups were rinsed with PBS and incubated for another $24 \mathrm{~h}$ without laser irradiation. The cells in the irradiated groups were exposed to 808 -nm laser light at $0.6 \mathrm{~W} / \mathrm{cm}^{2}$ for $5 \mathrm{~min}$ and incubated for another $24 \mathrm{~h}$. Then, cell viabilities were assessed by performing CCK- 8 assays. In addition, cell viabilities were also assessed in the presence of $\mathrm{NaN}_{3}$ or at low temperature to verify the participation and individual therapeutic efficacies of PDT and PTT. MG63/Dox cells were seeded in 96-well plates $\left(5 \times 10^{3}\right.$ cells/well in $\left.100 \mu \mathrm{L}\right)$ and incubated for $24 \mathrm{~h}$. Then, TPP-PPG@ICG was added at various concentrations. $\mathrm{NaN}_{3}$ was added to cell culture medium at $100 \mathrm{mM}$ to quench singlet oxygen molecules and thereby block the effect of PDT. Cells were irradiated at $4{ }^{\circ} \mathrm{C}$ to maintain a constant temperature and nullify the effect of PTT. Negative-control groups were treated with the laser only or with TPP-PPG@ICG without irradiation. The cells in the irradiated groups were exposed to $808-\mathrm{nm}$ laser light at $0.6 \mathrm{~W} / \mathrm{cm}^{2}$ for $5 \mathrm{~min}$ and incubated for another $24 \mathrm{~h}$. Subsequently, cell viabilities were assessed by performing CCK- 8 assays.

Calcein AM/PI co-staining was also performed to assess the synergistic phototherapeutic effect of TPPPPG@ICG. For visualization, MG63/Dox cells $\left(1 \times 10^{5}\right.$ cells per well) were first seeded in 6-well plates and incubated overnight. Then, the cells were treated with equivalent dosages of PBS (-), TPP-PPG@ICG (-), ICG $(+)$, TPP-PPG $(+)$, PPG@ICG $(+)$, or TPP-PPG@ ICG $(+)($ NGO $20 \mu \mathrm{g} / \mathrm{mL}$; ICG $15 \mu \mathrm{M})$ for $24 \mathrm{~h}$, where "(-)" indicates that no irradiation was applied, and "(+)" indicates that the cells were irradiated at $0.6 \mathrm{~W} / \mathrm{cm}^{2}$ for 
$5 \mathrm{~min}$. After incubation for another $24 \mathrm{~h}$, the cells were incubated with calcein AM (to visualize live cells) and PI (to visualize dead/late apoptotic cells), according to the manufacturer's suggested protocol.

\section{Detection of apoptosis and intracellular ROS}

MG63/Dox cells were seeded overnight in 6-well plates $\left(2 \times 10^{5}\right.$ cells per well $)$ and then treated for $24 \mathrm{~h}$ with equivalent dosages of PBS (-), TPP-PPG@ICG (-), ICG $(+)$, TPP-PPG $(+)$, PPG@ICG $(+)$, or TPP-PPG@ ICG $(+)$, where " $(-)$ " indicates that no irradiation was applied, and " $(+)$ " indicates that the cells were irradiated at $0.6 \mathrm{~W} / \mathrm{cm}^{2}$ for $5 \mathrm{~min}$ ) (NGO equivalent, $20 \mu \mathrm{g} /$ $\mathrm{mL}$; ICG equivalent, $15 \mu \mathrm{M})$. The cells were collected at $6 \mathrm{~h}$ post-laser irradiation after careful trypsinization and low-speed centrifugation, followed by washing twice with PBS. The collected cells were resuspended in $100 \mu \mathrm{L}$ binding buffer and stained with $2 \mu \mathrm{L}$ annexin V-FITC and $2 \mu \mathrm{L}$ PI for $15 \mathrm{~min}$ at room temperature in the dark. After staining, the cells were collected via low-speed centrifugation, washed twice with PBS, and diluted with $400 \mu \mathrm{L}$ binding buffer for flow cytometric analysis using an Epics XL-MCL instrument (Beckman Coulter).

The $2^{\prime}, 7^{\prime}$-dichlorodihydrofluorescein diacetate (DCFHDA) Kit was used to detect the intracellular ROS generation. MG63/Dox cells were seeded overnight in 24-well plates $\left(1 \times 10^{5}\right.$ cells per well $)$ and then treated with equivalent dosages of PBS $(-)$, TPP-PPG@ICG $(-)$, ICG $(+)$, TPP-PPG $(+)$, PPG@ICG $(+)$, or TPP-PPG@ICG $(+)$ (NGO equivalent, $20 \mu \mathrm{g} / \mathrm{mL}$; ICG equivalent, $15 \mu \mathrm{M}$ ) for $24 \mathrm{~h}$, where " $(-)$ " indicates that no irradiation was applied and " $(+)$ " indicates that the cells were irradiated at $0.6 \mathrm{~W} / \mathrm{cm}^{2}$ for $5 \mathrm{~min}$. After irradiation, the cells were promptly washed with PBS and incubated with $10 \mu \mathrm{M}$ DCFH-DA at $37^{\circ} \mathrm{C}$ for $30 \mathrm{~min}$. ROS FL signals were evaluated using a DMLRB inverted FL microscope (Leica).

\section{Detecting the mitochondrial membrane potential}

Changes in the mitochondrial membrane potential were measured using JC-1 and imaged using a CLSM. Briefly, MG63/Dox cells $\left(1 \times 10^{5}\right.$ cells per well $)$ were incubated with equivalent dosages of PBS (-), TPP-PPG@ICG (-), ICG (+), TPP-PPG (+), PPG@ICG (+), or TPP-PPG@ ICG (+) (NGO equivalent, $20 \mu \mathrm{g} / \mathrm{mL}$; ICG equivalent, $15 \mu \mathrm{M})$, where "( -$)$ " indicates that no irradiation was applied and " $(+)$ " indicates cases where the cells were irradiated for $24 \mathrm{~h}$. The irradiated groups were then illuminated using a laser at $808 \mathrm{~nm}\left(0.6 \mathrm{~W} / \mathrm{cm}^{2}, 5 \mathrm{~min}\right)$ and incubated for another $24 \mathrm{~h}$. The non-irradiated groups were incubated for $48 \mathrm{~h}$ under the same conditions. Then, the cells were promptly washed with PBS and incubated with $5 \mathrm{mM} \mathrm{JC}-1$ at $37^{\circ} \mathrm{C}$ for $30 \mathrm{~min}$. The cells were rinsed again with PBS and analyzed using a CLSM.

\section{Detection mitochondrial superoxide levels}

Mitochondrial superoxide generation was assessed by measuring MitoSOX FL using a CLSM. Briefly, MG63/ Dox cells were seeded in glass-bottom $35-\mathrm{mm}$ plates overnight and then treated with equivalent dosages of PBS $(-)$, TPP-PPG@ICG $(-), \operatorname{ICG}(+)$, TPP-PPG $(+)$, PPG@ICG (+), or TPP-PPG@ICG (+) (NGO equivalent, $20 \mu \mathrm{g} / \mathrm{mL}$; ICG equivalent, $15 \mu \mathrm{M})$, where " $(-)$ " indicates that no irradiation was applied and " $(+)$ " indicates cases where the cells were irradiated at $0.6 \mathrm{~W} / \mathrm{cm}^{2}$ for $5 \mathrm{~min}$. After treatment, the cells were washed twice with PBS, incubated with $5 \mu \mathrm{M}$ MitoSOX for $10 \mathrm{~min}$, washed twice with PBS, and analyzed using a CLSM.

\section{ATP determination assay}

A standard curve was generated for a series of ATP concentrations, using an ATP Determination Kit. MG63/ Dox cells were seeded in 96-well plates $\left(1 \times 10^{4}\right.$ cells per well) in $100 \mu \mathrm{L}$ of DMEM and incubated for $24 \mathrm{~h}$ prior to performing ATP-determination assays. Then, the cells were treated with equivalent dosages of PBS (-), TPPPPG@ICG (-), ICG (+), TPP-PPG (+), PPG@ICG (+), or TPP-PPG@ICG (+) (NGO equivalent, $20 \mu \mathrm{g} / \mathrm{mL}$; ICG equivalent, $15 \mu \mathrm{M})$, where " $(-)$ " indicates that no irradiation was applied and " $(+)$ " indicates cases where the cells were irradiated at $0.6 \mathrm{~W} / \mathrm{cm}^{2}$ for $5 \mathrm{~min}$. After $6 \mathrm{~h}$ of incubation, the culture medium was removed, and the cells were treated with lysis buffer. Next, the reagents of the ATP Determination Kit were added to the lysed cells, and a plate reader was used to measure the luminescence in order to calculate each ATP concentration. Each experiment was repeated thrice, and mean values were calculated.

\section{NIR FL and thermal imaging}

In vitro thermal imaging of the PBS blank, ICG, and TPP-PPG@ICG under irradiation $\left(808 \mathrm{~nm}, 0.6 \mathrm{~W} / \mathrm{cm}^{2}\right.$, 5 or $10 \mathrm{~min}$ ) was conducted using an infrared thermalimaging camera (Ti32, Fluke, USA). TPP-PPG@ICG was injected via the tail vein $(0.5 \mathrm{mg} / \mathrm{kg})$ into athymic nude mice bearing MG63/Dox tumor xenografts to evaluate the tumor-targeting ability. In vivo NIR imaging was taken from 0 to $48 \mathrm{~h}$ after injection with an in vivo NIR Imaging System (Kodak). Thermal imaging of blank PBS and TPP-PPG@ICG under irradiation $(808$ nm, 0.6 W/ $\mathrm{cm}^{2}, 5 \mathrm{~min}$ ) was recorded by an infrared thermal imaging camera (Ti32, Fluke, USA). All the sets and imaging conditions were the same as those of the reported method 
[38]. The major organs that were excised were imaged after sacrificing the nude mice that were intravenously administered with TPP-PPG@ICG at 24 h post-injection. Regional body temperatures and infrared thermographic maps were obtained using a Ti27 infrared thermal imaging camera (Fluke).

\section{Combined in vivo treatment with PDT and PTT}

When the tumor volume reached $60 \mathrm{~mm}^{3}$, the tumorbearing mice were randomly divided into six groups, with five mice per group. These groups included the PBS-treated, non-irradiated group (control group); the TPP-PPG@ICG-treated, non-irradiated group; the ICGtreated, irradiated group; the TPP-PPG-treated, irradiated group; the PPG@ICG-treated, irradiated group; and the TPP-PPG@ICG-treated, irradiated group. Equivalent dosages of the therapeutic agents were injected intravenously (ICG equivalent, $750 \mu \mathrm{M}$ ). In addition, for the irradiation groups, laser irradiation at $808 \mathrm{~nm}(0.6 \mathrm{~W} /$ $\mathrm{cm}^{2}, 5 \mathrm{~min}$ ) was applied at the tumor site. Variations in tumor volumes and body weights in each group were monitored every 3 days for up to 15 days to evaluate the therapeutic effects. Then, the animals were euthanized on day 15 . The tumors and major organs (the heart, liver, spleen, lungs, and kidneys) were collected. H\&E and TUNEL staining of tumor sections from different groups were performed, and the stained samples were observed under a bright-field microscope (Olympus).

\section{In vivo toxicity assessment}

The $200 \mu \mathrm{L}$ TPP-PPG@ICG (ICG equivalent, $750 \mu \mathrm{M}$ ) was injected intravenously into five healthy male nude mice. Another five nude mice injected with normal saline were selected as the control group. Then, at days 30, the blood was collected from each mouse for the blood chemistry test and complete blood panel analysis.

\section{Statistical analysis}

All statistical analyses were performed with SPSS 13.0 software. Data were presented as mean \pm standard deviation. The significance of the data is analyzed according to a Student's t-test: " $\mathrm{P}<0.01$.

\section{Results and discussion}

\section{Synthesis and characterization of TPP-PPG@ICG}

Based on the modified-Hummer's method, NGO preparation was initiated by the oxidization of graphite sheets, which was followed by ultrasonication [37]. Then, PG was prepared via a ring-opening nucleophilic addition reaction between the amine groups of the amino-terminated PEG (average molecular weight: $5000 \mathrm{Da}$ ) and the epoxy groups of NGO, according to our previously developed method [28-31]. This PEGylation method generated individual small NGO nanosheets with carboxyl functional groups at their edges, which were subsequently covalently conjugated with BPEI (average molecular weight: $1800 \mathrm{Da}$ ). Well-dispersed PPG was prepared and functionalized with abundant amine groups using this modification. Subsequently, TPP (a mitochondria-targeting ligand) was conjugated to the surface of the nanocomposite (TPP-PPG). Finally, ICG was absorbed onto TPP-PPG via $\pi-\pi$ stacking and hydrophobic interactions to obtain the TPP-PPG@ICG nanocomposite. Then, the TPP-PPG@ICG nanocomposite was purified via ultrafiltration and washed with 50\% isopropyl alcohol repeatedly until FL in the filtrate could not be detected by NIR [39-43].

The size, thickness, and morphology of the TPP-PPG@ ICG nanocomposite were characterized using AFM. As shown in Fig. 1a-d, the TPP-PPG@ICG nanocomposite formed small sheets measuring approximately $20-50 \mathrm{~nm}$ on one side ( $\sim 1 \mathrm{~nm}$ thickness). Successful ICG loading was evident in the UV-vis-NIR absorbance and FT-IR spectra of the aqueous dispersions (Fig. 1e, f). The results showed that TPP-PPG@ICG exhibited characteristic absorbance peaks of PPG $(281 \mathrm{~nm})$ and a characteristic broad absorption of TPP-PPG@ICG in the NIR region, ranging from 700 to $800 \mathrm{~nm}$. These data confirmed the successful loading of ICG onto PPG. Meanwhile, the hydrodynamic diameters of TPP-PPG and TPP-PPG@ ICG in water were detected by a DLS test. Depending on the DLS value, the mean diameters of the TPP-PPG and TPP-PPG@ICG in water were approximately $103 \mathrm{~nm}$ and $115 \mathrm{~nm}$, respectively (Additional file 1: Fig. S1).

The stabilities of TPP-PPG@ICG in phosphate-buffered saline (PBS, pH 7.4), Dulbecco's modified Eagle's medium (DMEM), or PBS $+10 \%$ fetal bovine serum (FBS) were compared (Additional file 1: Fig. S2a). After direct centrifugation at $5000 \mathrm{rpm} \mathrm{min}^{-1}$ for $10 \mathrm{~min}$, no precipitation was observed. Then, the ultrafiltration tubes $(10 \mathrm{kda})$ were used to collect the filtrate. As shown in Additional file 1: Fig. S2a, the pale green was observed in the filtrate except for those derived from media, suggesting a little ICG was filtered out. The results showed that TPP-PPG loaded with ICG via $\pi-\pi$ stacking and hydrophobic interactions was stable, which is important for the ability of PPG to serve as a carrier to deliver PS agents or drugs into tumor cells via the EPR effect after intravenous injection $[44,45]$. In order to research how much of the loaded ICG is released after incubation with PBS, DMEM and PBS $+10 \%$ FBS, the UV-vis peak at $790 \mathrm{~nm}$ was recorded to determine the changes before/ after incubation. The release of the ICG was calculated after subtraction of absorbance contributed by TPP-PPG. As displayed in Additional file 1: Fig. S2b, it was discovered that the released rate of ICG from TPP-PPG@ 

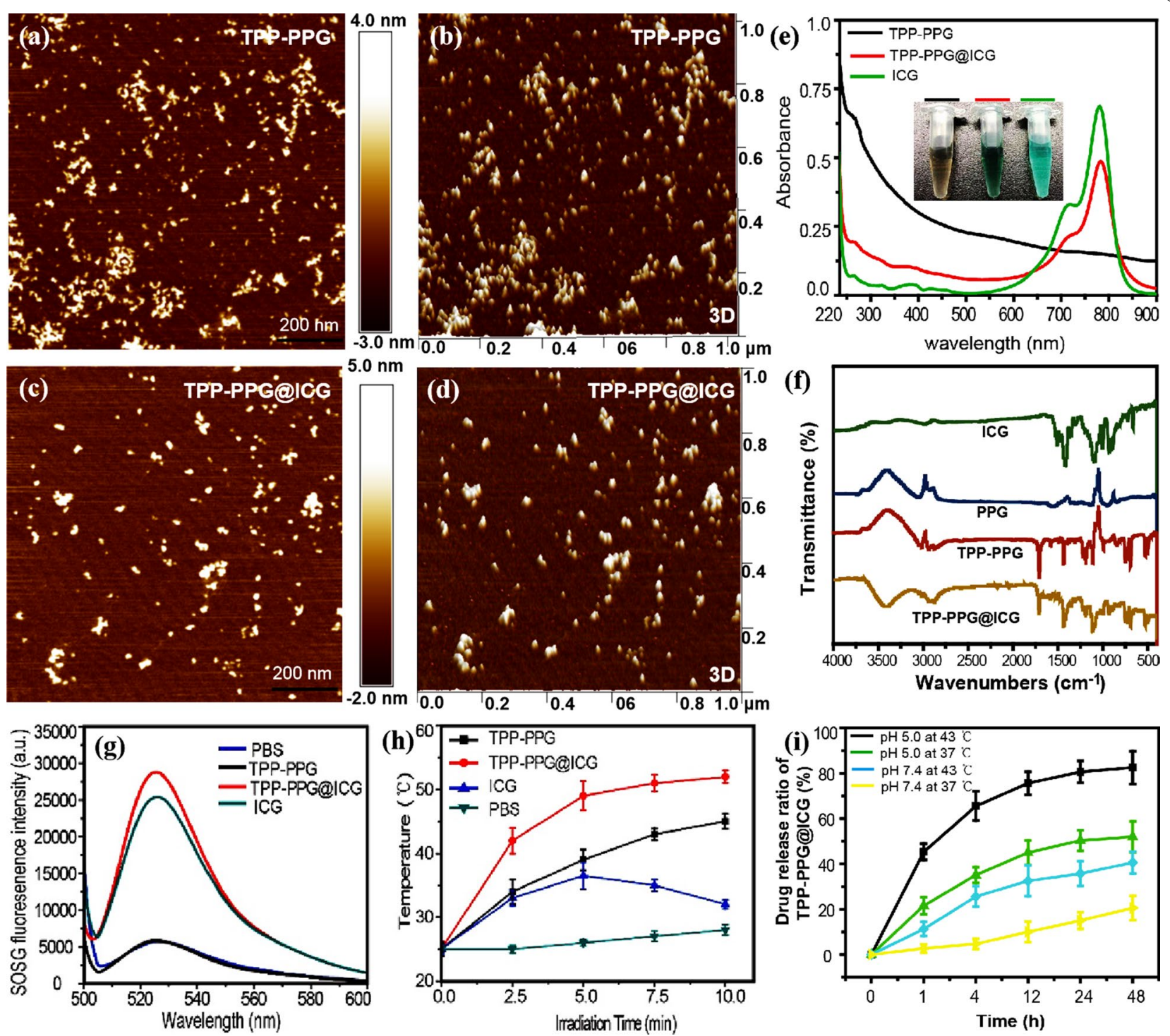

Fig. 1 Characterization and physicochemical properties of TPP-PPG@ICG. Atomic force microscopy (AFM)-based morphological characterizations of a-d TPP-PPG and TPP-PPG@ICG. e UV-vis absorption spectra the indicated materials. The inset shows photographs of aqueous solutions of TPP-PPG, TPP-PPG@ICG, and ICG. f FT-IR spectra of ICG, PPG, TTP-PPG, and TPP-PPG@ICG. $\mathbf{g}$ FL intensity of SOSG at 530 nm in PBS, TPP-PPG, TPP-PPG@ICG, and ICG after laser irradiation at $808 \mathrm{~nm}\left(0.6 \mathrm{~W} / \mathrm{cm}^{2}, 5 \mathrm{~min}\right)$. $\mathbf{h}$ Heating curves of PBS, ICG, TPP-PPG@ICG, and TPP-PPG during a 10-min irradiation. $\mathbf{i}$ ICG-release rate of TPP-PPG@ICG in acidic $(\mathrm{pH}=5.0)$ and alkalescent PBS $(\mathrm{pH}=7.4)$ at $37^{\circ} \mathrm{C}$ and $43^{\circ} \mathrm{C}$

ICG was $17.2 \%, 15.2 \%$ and $18.5 \%$ in PBS, DMEM and PBS $+10 \%$ FBS, respectively. Noticeably, there is a small amount of loss because some ICG was adhered to the ultrafiltration tube (Additional file 1: Fig. S2a). Hence, the results showed that the only little ICG release from TPP-PPG@ICG after incubation with PBS, DMEM and PBS + 10\%FBS, suggesting the TPP-PPG@ICG were stable in the physiological solutions.

To further demonstrate the stability of TPP-PPG@ ICG in PBS and PBS $+10 \%$ FBS, we performed the DLS test. As exhibited in Additional file 1: Fig. S3, the hydrodynamic size of the TPP-PPG@ICG in PBS and PBS $+10 \%$ FBS (approximately 140-160 $\mathrm{nm}$ ) were slightly increased compared with those in water (approximately $115 \mathrm{~nm}$ ) and exhibited no significant changes over the course of $24 \mathrm{~h}$, suggesting that the nanoparticles are highly stable in physiological solution. This result was consistent with that of centrifugation shown in Additional file 1: Fig. S2. Moreover, an ICG-loading efficiency of $0 \%$ to $30.4 \%$ was achieved by adjusting the ICG: TPPPPG weight ratio (Additional file 1: Fig. S4), which is 
calculated according to the standard curve for ICG is shown in Additional file 1: Fig. S5.

The photodynamic property of TPP-PPG@ICG was assessed by determining its ability to generate singlet oxygen $\left({ }^{1} \mathrm{O}_{2}\right)$ based on the FL signal of singlet oxygen sensor green (SOSG), a highly sensitive ${ }^{1} \mathrm{O}_{2}$ indicator. SOSG was added to different solutions of PBS or ICG $(15 \mu \mathrm{M})$, TPP-PPG@ICG (equivalent to $15 \mu \mathrm{M}$ ICG), or TPP-PPG (NGO $20 \mu \mathrm{g} / \mathrm{mL}$ ) in PBS, and irradiated for 5 min with a laser at $808 \mathrm{~nm}$ (power density: $0.6 \mathrm{~W} /$ $\mathrm{cm}^{2}$ ). Considerably higher SOSG FL intensity at $530 \mathrm{~nm}$ was observed in the ICG and TPP-PPG@ICG solutions than in the blank PBS and TPP-PPG solutions (Fig. 1g), indicating that TPP-PPG@ICG could act as a PS for PDT applications. The photothermal effect of TPP-PPG@ICG was evaluated by determining the temperatures of different samples after exposure to laser irradiation at $808 \mathrm{~nm}$. The results showed that the temperature of the PBS blank increased slowly from 25 to $26^{\circ} \mathrm{C}$ within 5 min of irradiation (Fig. 1h). However, the temperature of TPP-PPG@ ICG, increased sharply from 25 to $48{ }^{\circ} \mathrm{C}$ with a $35.8 \%$ photothermal conversion efficiency, which could lead to irreversible damage to tumor cells. It is also noteworthy that the photothermal-generation abilities of TPP-PPG and TPP-PPG@ICG increased proportionally with the duration of laser irradiation, whereas the photothermal-generation ability of ICG first increased and then decreased.

To demonstrate hyperthermia and $\mathrm{pH}$ trigged drug release, the drug release from the TPP-PPG@ICG were comparatively investigated in $37{ }^{\circ} \mathrm{C}$ and $43{ }^{\circ} \mathrm{C}$ while the $\mathrm{pH}$ value at 5.0 and 7.4. As shown in Fig. 1i, the ICG release from TPP-PPG@ICG at $37{ }^{\circ} \mathrm{C}$ and $\mathrm{pH} 7.4$ was very low, only about $15 \%$ of the total loaded ICG was released after $48 \mathrm{~h}$. However, the release of ICG was significantly accelerated at $43{ }^{\circ} \mathrm{C}$ and $\mathrm{pH} 5.0$, reaching a cumulative release of about $42.5 \%$ of total loaded drug in $1 \mathrm{~h}$ and $79.2 \%$ in $24 \mathrm{~h}$. This may be due to that the $\pi-\pi$ stacking interaction between ICG and TPP-PPG became weaker at acidic microenvironment and hyperthermia, which could not efficiently load the drug. Collectively, the release of the loaded ICG from the nanoparticles was found to follow a complex temperature and $\mathrm{pH}$ value dependent relationship. Therefore, if the TPP-PPG@ICG is located in acidic microenvironment and high temperature, ICG could release from TPP-PPG to have a superior synergistic therapeutic effect.

The IR thermal images (Fig. 2a) of blank PBS, ICG, and TPP-PPG@ICG in vitro during 5 and 10 min of irradiation were recorded, and the results also indicated that TPP-PPG@ICG continuously generated greater heat than the PBS blank or ICG, whereas ICG showed attenuated photothermal generation during long-time irradiation. These results demonstrated that the ICG can undergo irreversible photochemical degradation upon NIR laser irradiation and that nanographene sheets can effectively avoid this intrinsic defect. These results demonstrated that TPP-PPG@ICG possessed stronger ROSand photothermal-generation abilities than TPP-PPG or ICG alone. Thus, combining both can result in synergistically improved phototherapy.

\section{In vitro synergistic phototherapeutic effects and cellular uptake of TPP-PPG@ICG}

To verify the drug resistance of the human OS cell line, different concentrations of doxorubicin $(0.5-2.5 \mu \mathrm{g} / \mathrm{mL})$ were added to the MG63 and the MG63/Dox cells in culture. The CCK- 8 assay results indicated that the viability
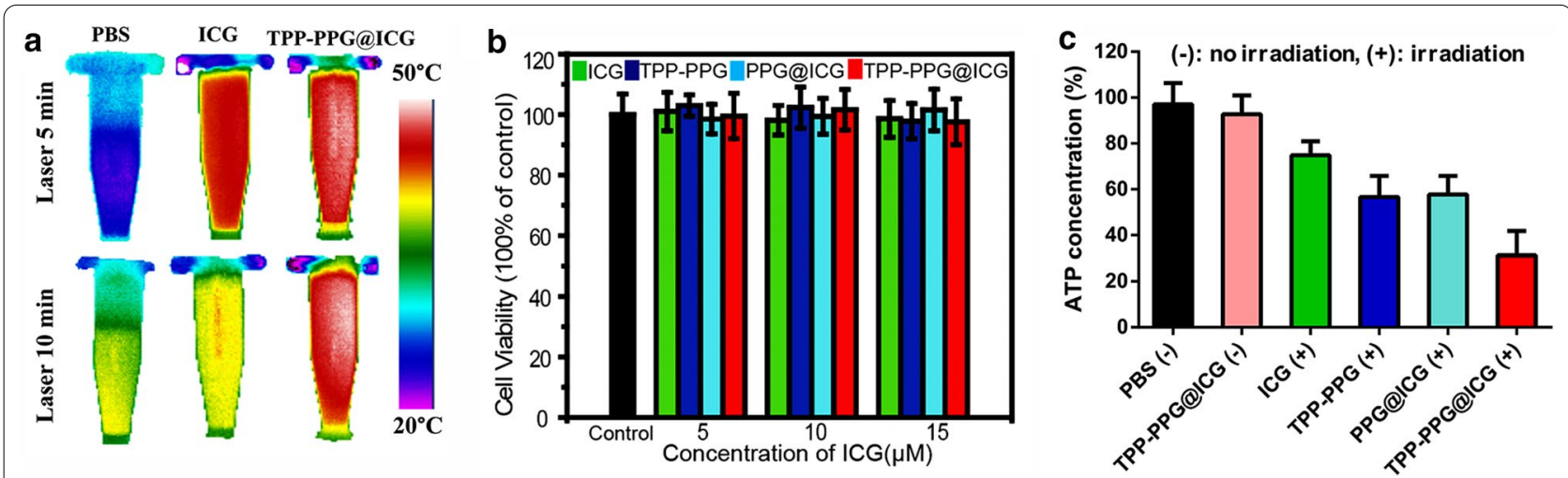

Fig. 2 a Thermal images of PBS, ICG, and TPP-PPG@ICG during a 5-min irradiation (upper row) or a 10-min irradiation (bottom row). b Cell Counting Kit-8 (CCK-8)-based viability assay performed with doxorubicin-resistant MG63 cells (MG63/Dox cells) treated with ICG, TPP-PPG, PPG@ICG, or TPP-PPG@ICG, without laser irradiation. c Relative intracellular ATP concentrations in the MG63/Dox cells after incubation with PBS, TPP-PPG@ICG, ICG, TPP-PPG, or PPG@ICG for $6 \mathrm{~h}$. Cells were treated with or without the NIR laser $\left(808 \mathrm{~nm}, 0.6 \mathrm{~W} / \mathrm{cm}^{2}\right)$ for $5 \mathrm{~min}$, and then their intracellular ATP concentrations were measured 
of the MG63/Dox cells remained above $90 \%$, whereas the viability of the MG63 cells was reduced to $24.9 \%$ when the doxorubicin concentration reached $2.5 \mu \mathrm{g} / \mathrm{mL}$ (Additional file 1: Fig. S6).

An in vitro phototherapeutic study of TPP-PPG@ICG was performed with the MG63/Dox cancer cells. Cellviability assays were conducted at $24 \mathrm{~h}$ post-irradiation $\left(0.6 \mathrm{~W} / \mathrm{cm}^{2}, 5 \mathrm{~min}\right)$ at an ICG-equivalent concentration ranging from 5 to $15 \mu \mathrm{M}$. The results of the CCK- 8 assays indicated that a negligible change occurred in the cell viabilities of non-irradiated groups treated with ICG, TPPPPG, PPG@ICG, or TPP-PPG@ICG (Fig. 2b). The cell viability of all groups was $>95 \%$, which indicated good biological compatibility. However, the cell viability of the irradiated groups gradually decreased with increasing concentrations of ICG, TPP-PPG, PPG@ICG, or
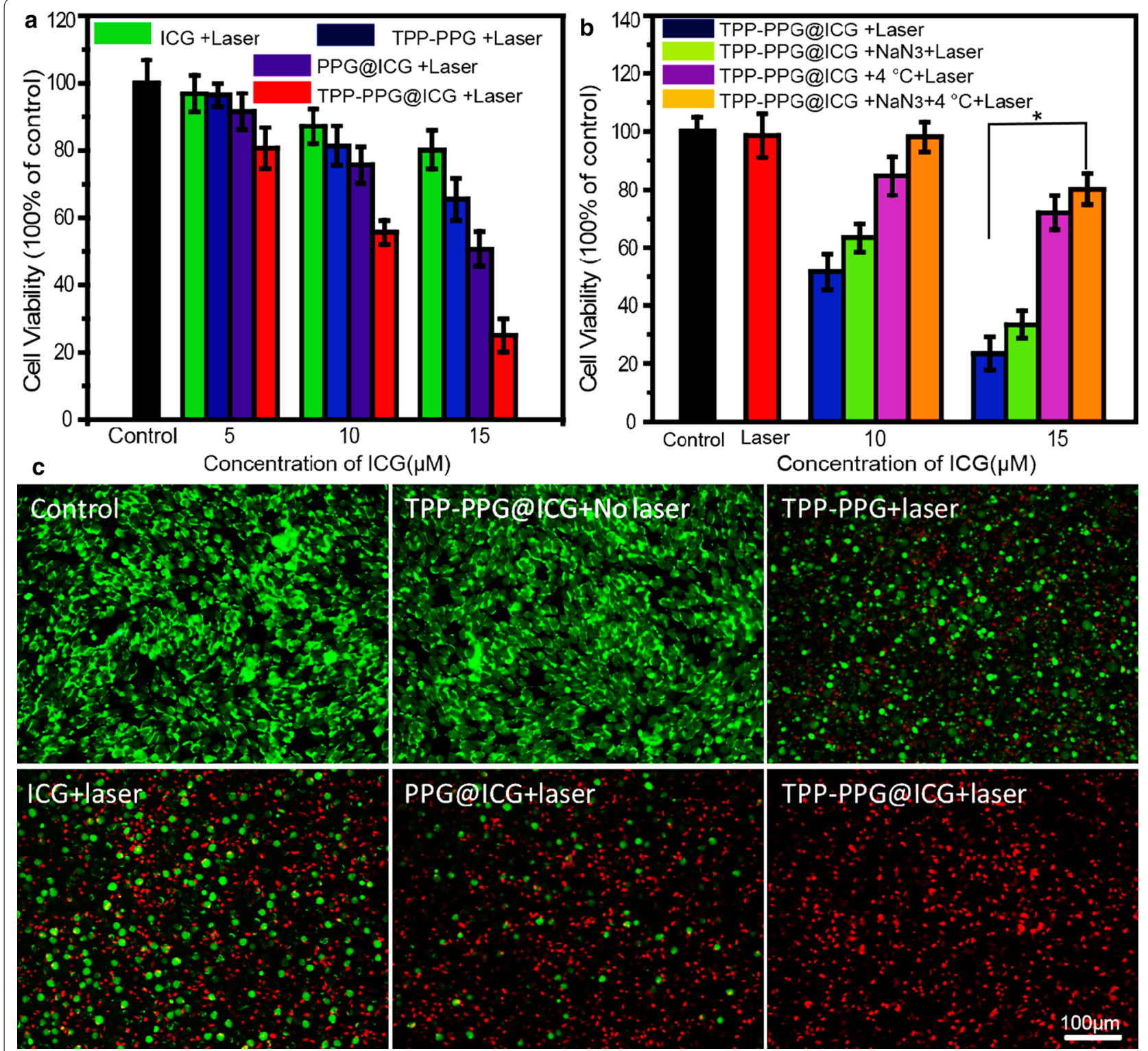

Fig. 3 Synergistic in vitro phototherapeutic effects of TPP-PPG@ICG and laser irradiation on MG63/Dox cells. a CCK-8 viability assay of MG63/ Dox cells treated with ICG, TPP-PPG, PPG@ICG, or TPP-PPG@ICG $24 \mathrm{~h}$ after laser irradiation at $808 \mathrm{~nm}$. b CCK-8 viability assays with MG63/Dox cells exposed to TPP-PPG@ICG at $24 \mathrm{~h}$ post-laser irradiation at $808 \mathrm{~nm}$, under conditions that inhibited PDT ( with $\mathrm{NaN}_{3}$ which quenches ${ }^{1} \mathrm{O}_{2}$ ) or PTT (with a low temperature to inhibit photothermal generation). c FL images of calcein AM + PI co-stained MG63/Dox cells after treatment with PBS, TPP-PPG, ICG, PPG@ICG, or TPP-PPG@ICG (ICG equivalent, $15 \mu \mathrm{M}$ ) at $24 \mathrm{~h}$ post-laser irradiation, or treatment with TPP-PPG@ICG without laser irradiation. $P$ values in $\mathbf{a}$ and $\mathbf{b}$ were calculated using student's t-test ( $\left.{ }^{*} \mathrm{p}<0.01\right)$ 
TPP-PPG@ICG (Fig. 3a). In particular, the phototoxicity of $15 \mu \mathrm{M}$ TPP-PPG@ICG was markedly higher than that of individual treatment with ICG, TPP-PPG, or PPG@ ICG treatments. The mitochondria-targeting TPP-PPG@ ICG nanocomposite showed stronger phototoxicity than the non-mitochondria-targeting nanocomposite, PPG@ ICG, which indicated that the efficacy of phototherapy was improved with mitochondria-targeted treatment. In order to research whether PDT or PTT works for the phototherapy effect, the cytotoxic effect of individual PDT and PTT was studied using sodium azide $\left(\mathrm{NaN}_{3}\right.$, which blocks the cytotoxic effect of ROS) and at $4{ }^{\circ} \mathrm{C}$ (to block the effect of PTT). As exhibited in Fig. 3b, the viabilities of the cells treated with TPP-PPG@ICG were $51.6 \%$ and $24.9 \%$ after treatment with $10 \mu \mathrm{M}$ or $15 \mu \mathrm{M}$ ICG, respectively. Interestingly, the cell-killing efficiency of TPP-PPG@ICG was markedly inhibited by treatment with $100 \mathrm{mM} \mathrm{NaN}_{3}$ (PTT alone), incubation at $4{ }^{\circ} \mathrm{C}$ (PDT alone) or the two treatments together, and the most inhibition effect was observed when the cells treated with $100 \mathrm{mM} \mathrm{NaN}_{3}$ and incubation at $4{ }^{\circ} \mathrm{C}$. Hence, PTT or PDT treatment alone did not completely kill the cells, as evident from the cell-viability assays. Otherwise, it is noteworthy that the killing efficacy of PTT alone was higher than that of PDT alone. Collectively, the results suggested that both PDT and PTT were collectively responsible for the cytotoxicity of TPP-PPG@ICG, with the effect of PTT representing the major cytotoxic mechanism.

Effective phototoxicity was further confirmed by performing calcein AM/propidium iodide (PI) double-staining assays with MG63/Dox cells after a 24-h incubation. Red and green FL from calcein AM and PI corresponded to dead and live cells, respectively. Cells in the control group and the group treated with TPP-PPG@ICG alone displayed green $\mathrm{FL}$, suggesting that these treatments were not toxic to MG63/Dox cells. In the TPPPPG + laser, ICG + laser, and PPG@ICG + laser groups, some cells were killed and displayed red FL. The TPPPPG@ICG + laser group induced most of cells death and exhibited intense red FL. These data further illustrate the synergistic therapeutic effect of mitochondria-targeting PDT and PTT (Fig. 3c).

Effective cellular uptake is particularly important for enhancing the penetration and retention of nano-anticancer drugs in tumor regions. To study intracellular, MG63/Dox cells were incubated with PBS or $15 \mu \mathrm{M}$ TPPPPG@ICG for 1 h, 4 h, 8 h, 12 h, and 24 h, after which they were analyzed by flow cytometry. The mean FL intensity of MG63/Dox cells treated with TPP-PPG@ICG increased in a time-dependent manner, showing a rapid uptake in the first $4 \mathrm{~h}$ after incubation and saturation at $12 \mathrm{~h}$ (Fig. 4a, b). These findings were consistent with the results of our previous studies, which showed that PEG- and BPEI-functionalized nanomaterials showed good cellular uptake ability when used as a delivery carrier [28-31]. The different uptake rates may also explain the higher phototoxicity of TPP-PPG@ICG than that of ICG at the same concentration. To examine subcellular localization, MG63/Dox cells were co-stained with the MitoTracker after incubation with TPP-PPG@ICG or PPG@ICG. FL-confocal microscopy images indicated that TPP-PPG@ICG accumulated in the mitochondria of tumor cells (Fig. 4c). This result confirmed the efficiency of mitochondrial targeting by TPP-PPG@ICG.

\section{Cellular mechanism of synergistic phototherapy}

Apoptosis has been reported to be the main mechanism of phototherapy [46]. Flow cytometry was used to evaluate the rate of apoptosis by assessing the fluorescein isothiocyanate (FITC)-labeled annexin V (annexin V-FITC) positivity of MG63/Dox cells, induced by TPP-PPG@ ICG. Relatively few MG63/Dox cells treated with (i) TPP-PPG@ICG without irradiation, (ii) TPP-PPG plus irradiation, or (iii) ICG plus irradiation were positive for annexin V-FITC staining. In contrast, MG63/Dox cells exposed to laser irradiation at $808 \mathrm{~nm}$ after TPP-PPG@ ICG treatment exhibited a significantly higher proportion of annexin V-FITC-positive cells (Fig. 5a, b). These results demonstrated that MG63/Dox cell death was mediated primarily via apoptosis.

PDT-induced apoptosis was mainly induced by intracellular ROS generation. Thus, to investigate the mechanism through which TPP-PPG@ICG killed the drug-resistant OS cells, we examined ROS generation in MG63/Dox cells irradiated with TPP-PPG@ICG using DCFH-DA. Intracellular ROS generation, which activates apoptosis, was recognized as the main cytotoxic mechanism associated with PDT treatment. DCFH-DA, a fluorimetric probe mainly used for oxidative stress measurements, is a non-fluorescent compound that can be transformed to a fluorescent compound (DCF) via an ROS-mediated oxidation reaction [47]. Accordingly, the intracellular FL intensity was measured to evaluate ROS generation using confocal FL microscopy. Green FL revealed the extent of intracellular ROS generation. Our results indicated that TPP-PPG@ICG generated negligible intracellular ROS without laser irradiation. After laser irradiation, intracellular ROS was generated to different extents in TPP-PPG-treated, ICG-treated, PPG@ICGtreated, and TPP-PPG@ICG-treated cells, among which, ROS generation was particularly robust in the TPPPPG@ICG-treated cells, demonstrating the occurrence of mitochondria-targeted ROS production (Fig. 5c).

As mentioned above, mitochondria are the central initiators of the intrinsic-apoptosis pathway, which makes 

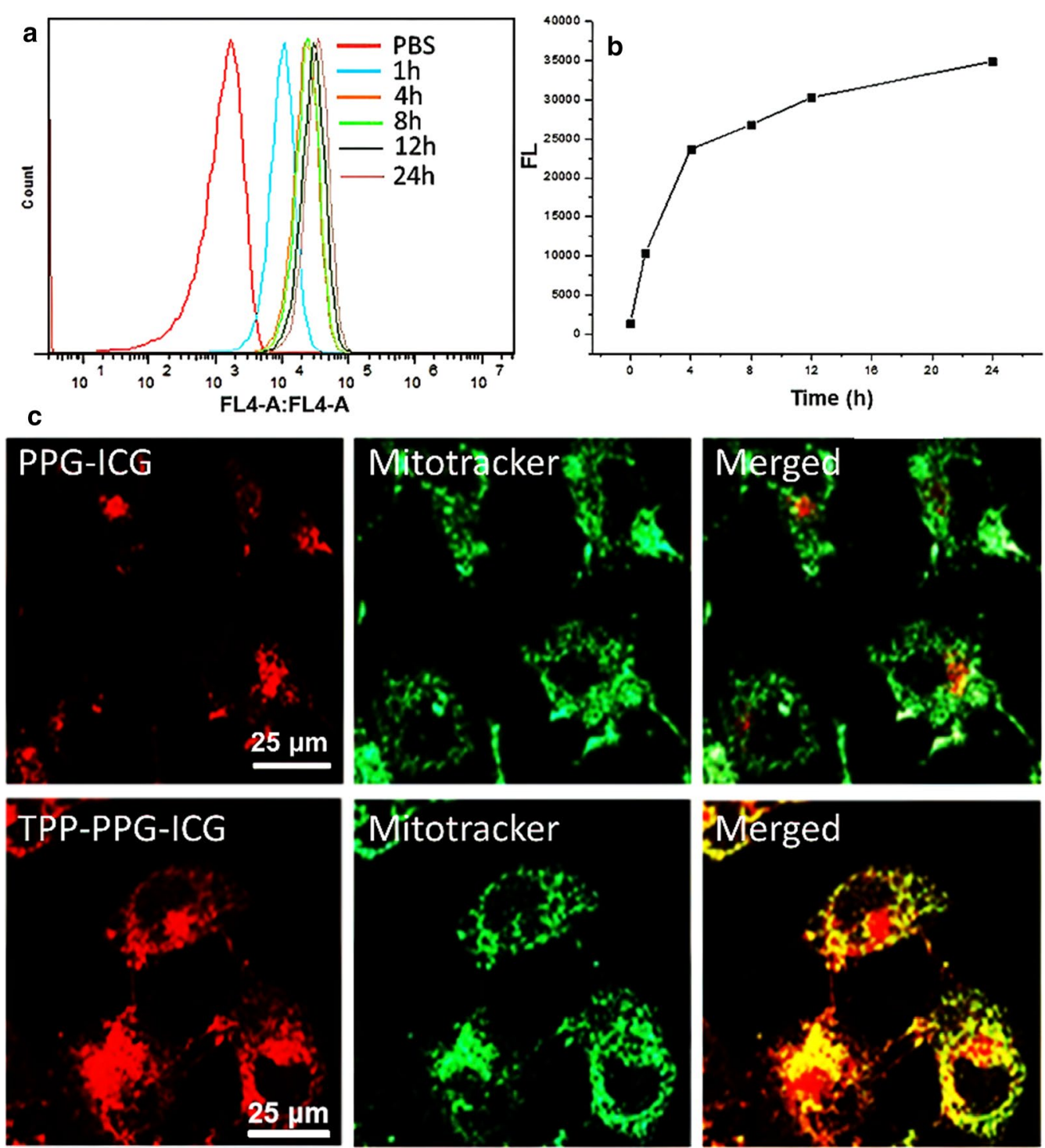

Fig. 4 Cellular uptake and subcellular localization. a The cellular uptake of TPP-PPG@ICG was measured by flow cytometry. b The mean FL intensity of MG63/Dox cells ( $n=10,000$ cells) was determined by flow cytometric analysis. c FL-confocal microscopic images of MG63/Dox cells co-treated with MitoTracker and either PPG@ICG orTPP-PPG@ICG are shown

them susceptible to photocytotoxicity. As TPP-PPG@ ICG has been hypothesized to target the mitochondria, we focused on a potential synergistic phototherapeutic effect of TPP-PPG@ICG on the mitochondria. We evaluated superoxide production in the mitochondria of MG63/Dox cells using the mitochondrial superoxide indicator, MitoSOX Red. As shown in Fig. 6a, MitoSOX Red exhibited red FL in TPP-PPG@ICG-treated cells after $5 \mathrm{~min}$ of photoirradiation, whereas no appreciable red FL was observed in TPP-PPG@ICG-treated cells without photoirradiation, and weak red FL was detected in TPP-PPG-treated, ICG-treated, or PPG@ICG-treated cells after photoirradiation. These findings indicated that ICG and NGO were delivered simultaneously to the mitochondria in the composite nanostructures and exerted a synergistic effect. Thus, TPP-PPG@ICG may cause photodamage to mitochondria and perturb their functions.

The mitochondrial membrane potential reflects the functional status of mitochondria, which has been hypothesized to be associated with tumorigenicity, cell differentiation, and malignancy [9]. A previous report showed that cancer cells possess higher mitochondrial membrane potentials than normal cells [48]. Therefore, 

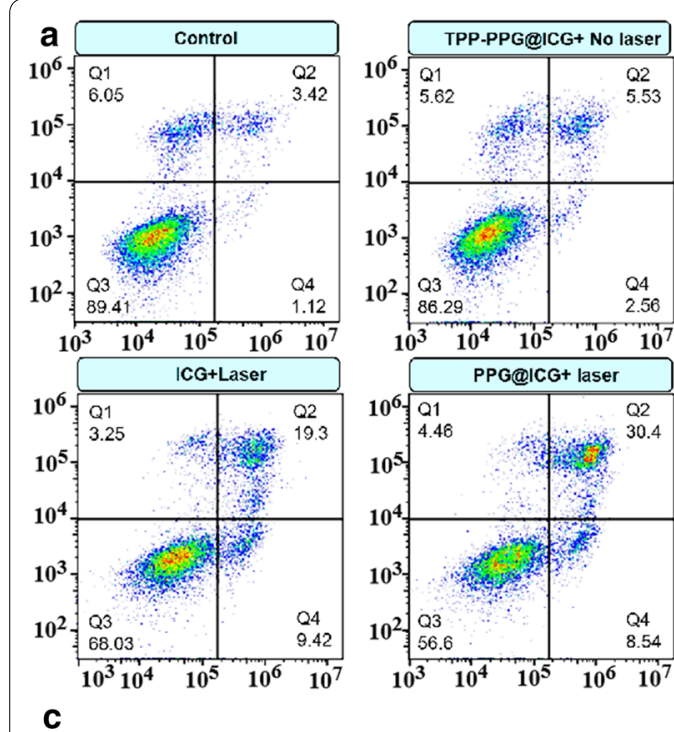
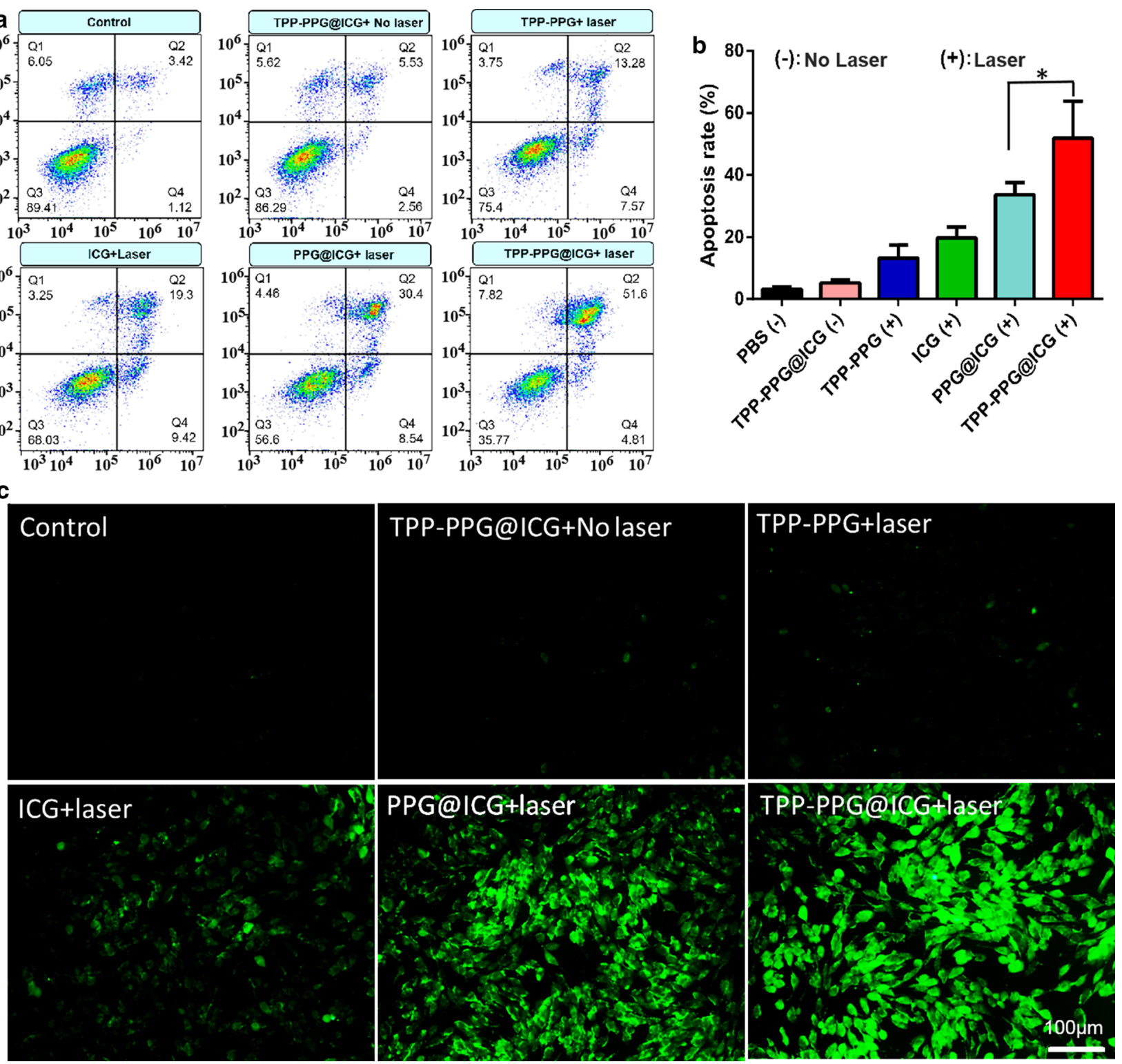

Fig. 5 Cellular mechanism of the synergistic phototherapy of TPP-PPG@ICG. MG63/Dox cells were treated with the PBS, TPP-PPG, ICG, PPG@ICG, orTPP-PPG@ICG (ICG equivalent, $15 \mu \mathrm{M}$ ) with laser irradiation, or with TPP-PPG@ICG without laser irradiation. The rate of apoptosis (a, b) and c ROS production was measured using flow cytometry and FL microscopy after incubation with annexin V-FITC/PI or DCFH-DA, respectively. P values in $\mathbf{b}$ were calculated using student's t-test $\left({ }^{*} p<0.01\right)$

cancer cells exhibiting a markedly reduced mitochondrial membrane potential show suppressed ATP production, slower proliferation, and severe impairment of tumorigenicity $[49,50]$. In this study, the mitochondrial membrane potential was studied by performing 5,5',6,6'-tetrachloro-1,1',3,3'-tetraethylbenzimidazoloca rbocyanine iodide (JC-1) assays. As a cationic dye, JC-1 can accumulate in the mitochondria to form aggregates (red FL) in the presence of a high mitochondrial membrane potential, or it may disperse in the cytoplasm as monomers (green FL) if the mitochondrial membrane potential is reduced [51]. As shown in Fig. 6b, green FL was observed in TPP-PPG@ICG-treated cells after $5 \mathrm{~min}$ of photoirradiation, whereas appreciable red FL appeared in TPP-PPG@ICG-treated cells without photoirradiation, and weak green FL appeared in TPP-PPG, ICG, or PPG@ICG-treated cells after photoirradiation. These variations confirmed the mitochondrial targeting of TPP-conjugated ICG and NGO (with irradiation) and their ability to synergistically disrupt the mitochondrial 


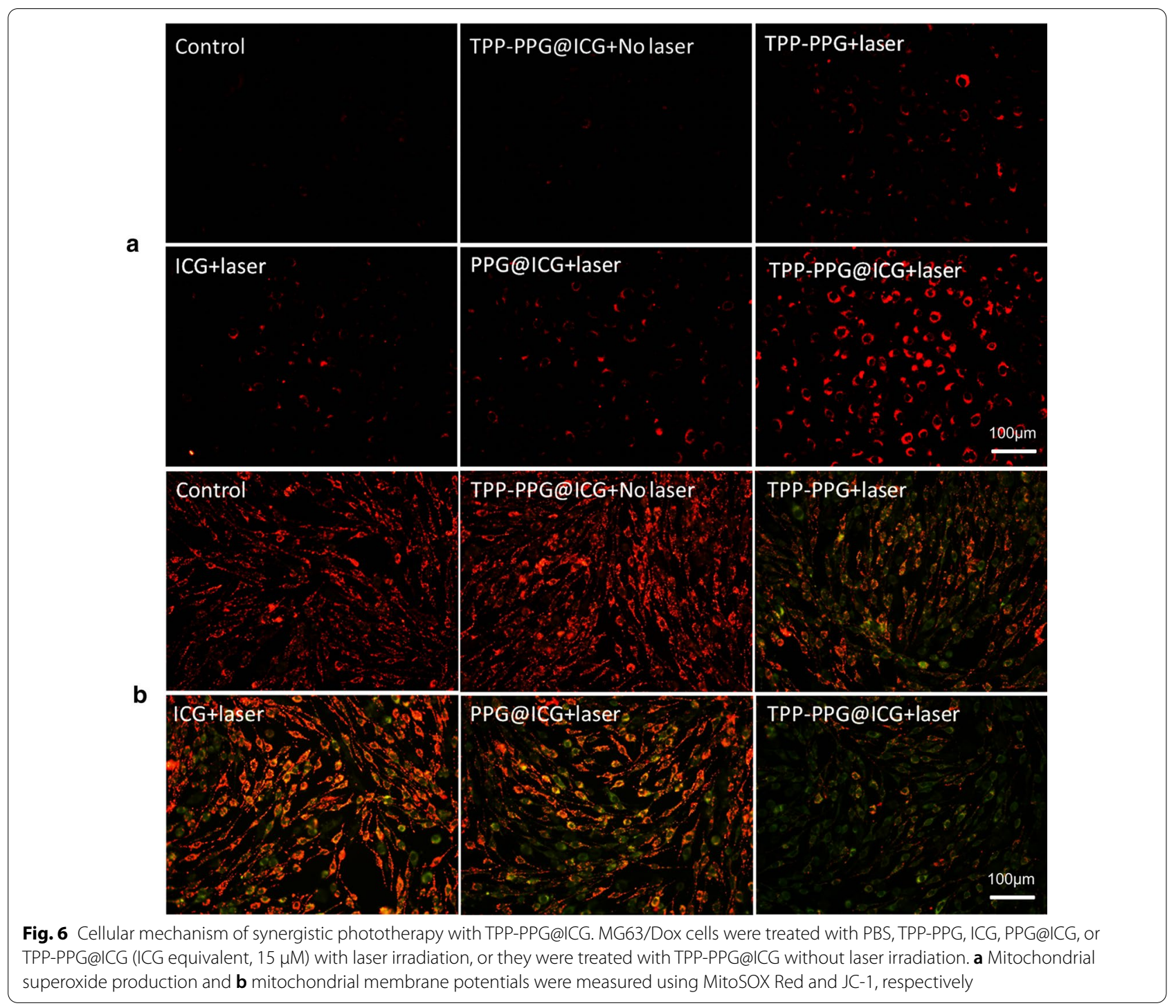

function. Thus, TPP-PPG@ICG treatment may photodamage the mitochondria and affect their function. It is well known that mitochondria are the major functional components of ATP production [52]. Next, we continued to explore if the synergistic phototherapeutic could influence the ATP production in MG63/Dox cells after irradiation. As shown in Fig. 2c, compared with other groups, the intracellular ATP concentration decreased tremendously in TPP-PPG@ICG-treated cells after $5 \mathrm{~min}$ of photoirradiation. These results demonstrated that TPP-PPG@ICG plus irradiation could inhibit the cellular ATP production and disturb the cancer cell energy supply, which could assist to inhibit the ATP-dependent efflux of anticancer drugs. Hence, the greater TPP-PPG@ ICG could enter the MG63/Dox cells to exert effect. As a result, the cancer cells were more sensitive to the damage induced by synergistic phototherapeutic.

Herein, based on the results of cellular uptake behavior, intracellular localization, intracellular ROS producing ability, ATP level, and so on, we hypothesize that the primary mechanism of the synergistic phototherapy of TPP-PPG@ICG. Aided by TPP-PPG, the significantly enhanced ICG delivery to the cell mitochondria was observed. Then, under the irradiation, ROS and hyperthermia were generated to perturb the mitochondrial membrane potentials, reduce the ATP production. Eventually, cell was death mediated by apoptosis. 


\section{In vivo tumor targeted NIR imaging and synergistic phototherapy}

Based on the FL imaging in vivo and synergistic phototherapy in vitro, we evaluated TPP-PPG@ICG for imaging-guided drug-resistant OS phototherapy in vivo. The in vivo PTT efficiency of TPP-PPG@ICG was investigated in male, nude mice bearing MG63/Dox tumor xenografts. TPP-PPG@ICG (10 mg/kg) was intravenously injected into the tumor-bearing naked mice. In vivo NIR fluorescence imaging was taken from 0 to $24 \mathrm{~h}$ after injection. As exhibited in Fig. 7a, the fluorescence intensity at the implanted tumors increased in time-dependent manner and strong fluorescence intensity was observed at $24 \mathrm{~h}$. Besides, dissected organs from the MG63/Dox tumor-bearing mice showed strong FL intensities in the tumors, but not in other organs, and their margins were clearly observable (Fig. 7c).

TPP-PPG@ICG (10 mg/kg) was intravenously injected into the tumor-bearing mice. At $24 \mathrm{~h}$ post-injection, in vivo IR thermal imaging was performed after a 5-min laser irradiation at $808 \mathrm{~nm}$. When the entire tumor tissue was under irradiation, temperature changes in the tumor xenografts were recorded using an IR thermal camera. As shown in Fig. 7b and Additional file 1: Fig. S7, after 5 min of NIR laser irradiation, the temperature of the PBS-treated tumors increased from $34{ }^{\circ} \mathrm{C}$ to $42-44{ }^{\circ} \mathrm{C}$. However, the temperature of tumors treated with the TPP-PPG@ICG increased to $60-62{ }^{\circ} \mathrm{C}$, which was sufficient to kill malignant cells. In contrast, no apparent temperature increase was observed in other body parts of the mice. NIR imaging and the preferential accumulation of TPP-PPG@ICG in tumors indicated that this approach can be used for localizing the tumor margin and administering precise real-time imaged-guided cancer phototherapy.

In addition, the relative growth rate of the MG63/Dox tumors was monitored after injection. Tumors treated with PBS or TPP-PPG@ICG without irradiation grew rapidly. The growth rate of tumors in the TPP-PPGtreated and ICG-treated groups irradiated with the 808-nm laser was slightly inhibited, suggesting partially suppressed tumor growth. However, the tumor volumes increased 3 days after irradiation. In addition, the tumor growth rate in the PPG@ICG-treated group exposed to 808-nm laser irradiation was further inhibited, which suggested that an enhanced inhibitory effect on tumor growth occurred due to the synergistic effect of PDT and PTT. Nevertheless, tumor volumes still increased from 6 days after irradiation. In contrast, tumor growth in the TPP-PPG@ICG-treated irradiation group was significantly inhibited, which suggested that mitochondrial targeting may considerably improve the efficacy of synergistic phototherapy (Fig. 7d, e). Mitochondria are sensitive to ROS and hyperthermia; hence, phototherapymediated damages can rapidly perturb the mitochondrial function, change the mitochondrial membrane potential, reduce ATP production, and finally induce apoptosis in tumor cells. In addition to suppressing ATP production, mitochondria-targeted synergistic phototherapy can effectively circumvent drug resistance by inhibiting the P-gP-dependent unidirectional expulsion of anticancer drugs. Therefore, mitochondria-targeted synergistic phototherapy acted as an efficient strategy against drug-resistant OS. Body weights were monitored during treatment for all treated groups. No significant differences were observed among the groups. (Fig. 7f).

To further study the phototherapeutic effects of TPPPPG@ICG, hematoxylin and eosin (H\&E) and terminal deoxynucleotidyl transferase dUTP nick end labeling (TUNEL) staining of the tumor sections were performed at $24 \mathrm{~h}$ post-irradiation. Without irradiation, the PBSand TPP-PPG@ICG-treated groups exhibited no tumor cell apoptosis or necrosis in the histological sections. Following irradiation, some sporadic necrosis was observed in the PPG@ICG-treated, which was more obvious than in the TPP-PPG-treated groups and ICG-treated group. In contrast, the most cancer cell apoptosis and necrosis occurred in the TPP-PPG@ICG-treated group, following irradiation. These findings indicated that treatment with TPP-PPG@ICG plus a single NIR laser (808 nm) synergistically enhanced the effects of PDT and PTT (Fig. $7 \mathrm{~g}$, $h$ and Additional file 1: Fig. S8 ).

Furthermore, major organs, including the heart, liver, spleen, lungs, and kidneys, were collected from mice administered with TPP-PPG@ICG, for H\&E staining to assess the side effect. The results showed that, compared to the degree of injury observed in the control group, injury was negligible after treatment with TPP-PPG@ ICG (Additional file 1: Fig. S9). Otherwise, in order to further investigate the biosafety of TPP-PPG@ICG, the

\footnotetext{
(See figure on next page.)

Fig. 7 In vivo synergistic phototherapy of TPP-PPG@ICG on MG63/Dox tumor xenografts. a NIR FL imaging of MG63/Dox tumor xenografts exposed to 808-nm laser irradiation (0.6 W/cm², $5 \mathrm{~min}), 0.5,1,4,8,12$ and $24 \mathrm{~h}$ after tail vein injection of TPP-PPG@ICG, and $\mathbf{c}$ the dissected organs from the MG63/Dox tumor-bearing mice: the tumor, the lungs, the liver, the spleen, the kidneys, the heart and the muscle). $\mathbf{b}$ IR thermal imaging of MG63/Dox tumor xenografts exposed to 808-nm laser irradiation (0.6 W/cm², 5 min), 24 h after tail vein injection with PBS and TPP-PPG@ICG. d Photographs of representative tumors resected from different groups on days 0, 7, and 14, as indicated. e Tumor volumes of MG63/Dox tumor xenografts, $\mathbf{f}$ body weights of different groups of mice, and $\mathbf{g}$ H\&E and $\mathbf{h}$ TUNEL staining of tumor sections of different groups. TUNEL-staining images for the control,TPP-PPG@ICG + no laser, and TPP-PPG + laser groups are shown in Additional file 1: Fig. S9)
} 


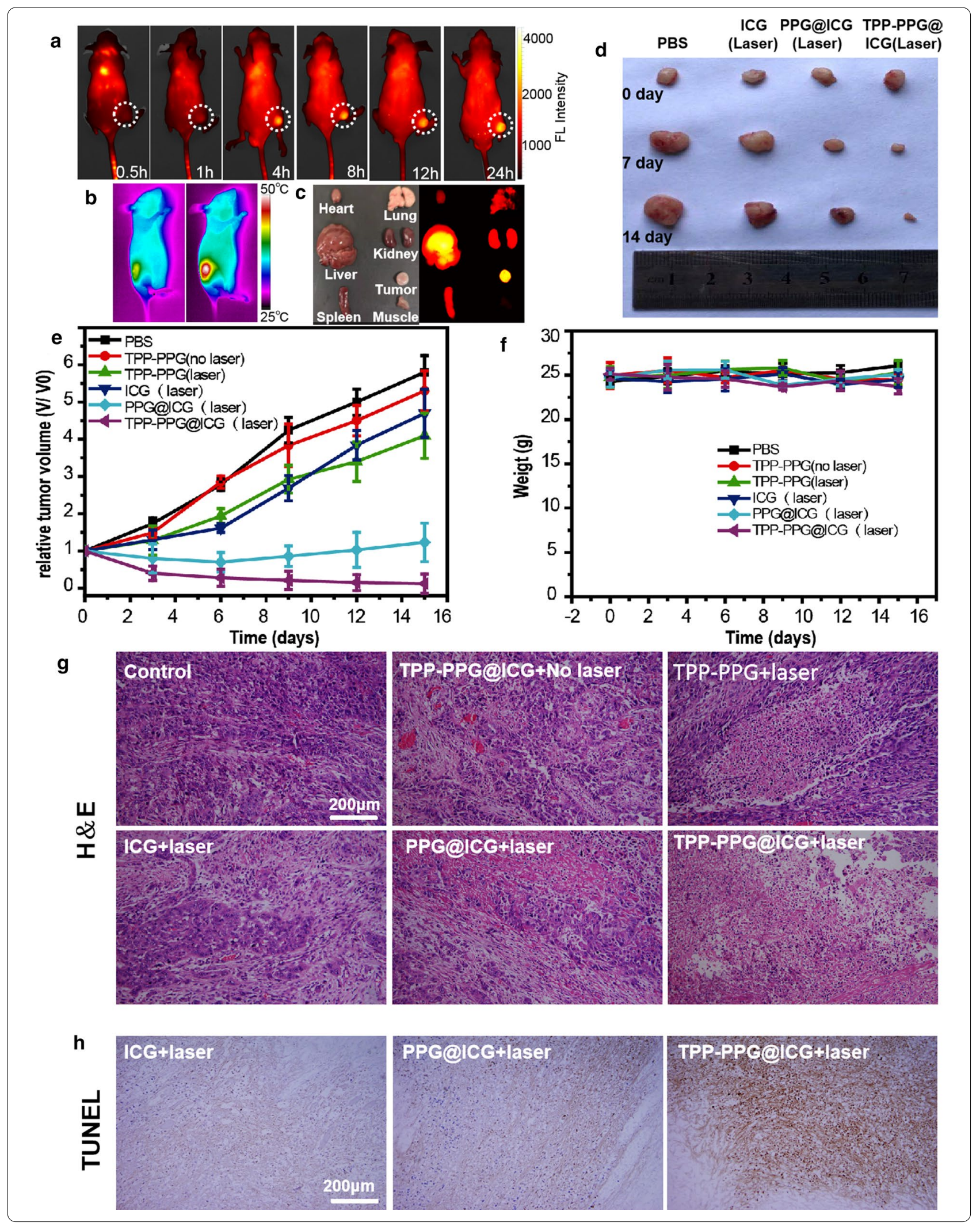


blood biochemistry was systematically performed. Alanine aminotransferase (ALT), aspartate aminotransferase (AST), and alkaline phosphatase (ALP) were selected to evaluate the liver function, while creatinine and urea nitrogen were measured to evaluate the kidney function. Meanwhile, the following important hematological markers: white blood cells (WBC), red blood cells (RBC), hematocrit (HCT), mean corpuscular volume (MCV), hemoglobin (HGB), platelets (PLT), mean corpuscular hemoglobin $(\mathrm{MCH})$, and mean corpuscular hemoglobin concentration (MCHC) were chosen to evaluate the potential toxicity of TPP-PPG@ICG. As exhibited in Additional file 1: Tables S1 and S2, all the parameters in the TPP-PPG@ICG treated groups appear to be normal compared with the control groups, and within the reference normal ranges at day 30 . Thus, the results exhibited that TPP-PPG@ICG showed high efficacy in tumor-targeted phototherapy with minimal side effects.

\section{Conclusions}

In summary, we developed a new NGO derivative (TPPPPG@ICG), which targets the mitochondria for FL image-guided synergistic phototherapy of drug-resistant OS. Owing to its preferential tumor accumulation, suitability for NIR imaging, and mitochondria-targeting ability, the TPP-PPG@ICG nanocomposite showed maximal phototherapeutic efficacy and minimal side effects. The PEG- and BPEI-functionalized NGO facilitated ICG dispersion and cellular uptake, whereas the mitochondriatargeted TPP simultaneously enhanced PDT/PTT cancer treatment and suppressed ATP production, which can serve as another effective strategy for surmounting drug resistance. The in vitro and in vivo phototherapy effects of TPP-PPG@ICG were significantly improved, leading to superior tumor eradication in drug-resistant OS models. The further improved novel nanocomposite shows promise for applications in highly sensitive FL imaging and efficient drug-resistant OS phototherapy. Thus, we expect that it has potential for therapeutic efficacy in prospective clinical trials.

\footnotetext{
Abbreviations

OS: Osteosarcoma; TPP: (4-Carboxybutyl) triphenyl phosphonium bromide; ATP: Adenosine triphosphate; P-gP: P-glycoprotein; PDT: Photodynamic therapy; PTT: Photothermal therapy; PS: Photosensitizer; ROS: Reactive oxygen species; NIR: Near-infrared; FL: Fluorescence; ICG: Indocyanine green; PEG: Polyethylene glycol; PEI: Polyethyleneimine; EDC: (3-Dimethylamino propyl- $\mathrm{N}^{\prime}$-ethylcarbodiimide) hydrochloride (EDC.HCl); NHS: N-Hydroxysuccinimide; SOSG: Singlet oxygen sensor green; PI: Propidium iodide; JC-1: 5,5',6,6'-tetrachloro-1, 1',3,3'-tetraethylbenzimidazolocarbocyanine iodide; CCK-8: Cell Counting Kit-8; FT-IR: Fourier transform infrared spectroscopy; AFM: Atomic force microscope; UV-vis-NIR: Ultraviolet-visible-infrared; CLSM: Confocal laser-scanning microscope; FL: Fluorescence; DCFH-DA: $2^{\prime}, 7^{\prime}$-dichlorodihydrofluorescein diacetate; H\&E: Hematoxylin and eosin; TUNEL: Terminal deoxynucleotidyl transferase dUTP nick end labeling staining; ALT: Alanine aminotransferase; AST: Aspartate aminotransferase; ALP: Alkaline phosphatase;
}

WBC: White blood cells; RBC: Red blood cells; HCT: Hematocrit; MCV: Mean corpuscular volume; HGB: Hemoglobin; PLT: Platelets; MCH: Mean corpuscular hemoglobin; MCHC: Mean corpuscular hemoglobin concentration.

\section{Supplementary Information}

The online version contains supplementary material available at https://doi. org/10.1186/s12951-021-00831-6.

\begin{abstract}
Additional file 1: Figure S1. The DLS analysis of the TPP-PPG and TPP-PPG@ICG. Figure S2. (a) The stabilities of TPP-PPG@ICG in PBS (A), in DMEM (B) and in PBS + 10\% FBS (C). The pictures of the ultrafiltration tube and the filtrate after centrifugation at $5000 \mathrm{rpm} \mathrm{min}^{-1}$ for $10 \mathrm{~min}$. (b) The UV-vis absorption spectra of the TPP-PPG@ICG incubation $24 \mathrm{~h}$ with $50 \%$ isopropanol, PBS, DMEM and PBS + 10\% FBS after the appropriate cleaning procedures performed. Figure S3. The DLS change curve of TPP-PPG@ICG in PBS or PBS + 10\% FBS. Figure S4. The effect of weight ratio of ICG and TPP-PPG on the ICG loading efficiency. Figure S5. The calibration curve of ICG in PBS with absorption at $790 \mathrm{~nm}$. Figure S6. The MG63/Dox cells showed resistance to Dox. Figure S7. The temperature variation of tumors after laser exposure. Figure S8. TUNEL staining of tumor sections of control group, TPP-PPG@ICG + No laser group and TPP-PPG + laser group. Figure S9. Negligible injury to the heart, the liver, the spleen, the lungs, and the kidneys after treatment with the TPP-PPG@ ICG. Table S1. Comparison between PBS and TPP-PPG@ICG groups of treatment on whole blood cell count. Table S2. Comparison between PBS and TPP-PPG@ICG groups of treatment on liver function and kidney function indicators.
\end{abstract}

\section{Authors' contributions}

All authors contributed to data analysis, drafting or revising the article, and agree to be accountable for all aspects of the work. All authors read and approved the final manuscript.

\section{Funding}

This work was supported by the National Natural Science Foundation of China (31800811, 81873987), China Postdoctoral Science Foundation (2019M653353), Sichuan University Project (135 Project of Dr. Zongke Zhou, ZYGD18026), Natural Science Foundation of Chongqing (cstc2019jcyjmsxmX0248, cstc2020jcyj-msxmX0178), Medical Science and Technology Innovation Fund of Chongqing General Hospital (Y2017ZDXM04), Basic Research and Frontier Exploration of Yuzhong District (20180135, 20190109).

Availability of data and materials

All data generated or analyzed during this study are included in this article and its Additional file.

\section{Declarations}

Ethics approval and consent to participate.

All animal experiments were approved by the Ethics Committee of the Chongqing General Hospital in accordance with the guidelines on animal care and use.

\section{Consent for publication}

Not applicable.

\section{Competing interests}

The authors declare that they have no competing interests.

\section{Author details}

${ }^{1}$ Department of Orthopedics, West China Hospital/West China School of Medicine, Sichuan University, Chengdu 610041, China. ${ }^{2}$ Department of Orthopedics, Chongqing General Hospital, University of Chinese Academy of Sciences, Chongqing 400014, China. ${ }^{3}$ Health Management Center, West China Hospital/ West China School of Medicine, Sichuan University, Chengdu 610041, China. 
Received: 4 January 2021 Accepted: 10 March 2021

Published online: 19 March 2021

\section{References}

1. Haghiralsadat F, Amoabediny G, Naderinezhad S, Zandieh-Doulabi B, Forouzanfar T, Helder MN. Codelivery of doxorubicin and JIP1 siRNA with novel EphA2-targeted PEGylated cationic nanoliposomes to overcome osteosarcoma multidrug resistance. Int J Nanomed. 2018;13:3853-66.

2. Bielack SS, Carrle D, Hardes J, Schuck A, Paulussen M. Bone tumors in adolescents and young adults. Curr Treat Options Oncol. 2008;9:67-80.

3. Hattinger CM, Fanelli M, Tavanti E, Vella S, Riganti C, Picci P, Serra M. Doxorubicin-resistant osteosarcoma: novel therapeutic approaches in sight? Future Oncol. 2017;13:673-7.

4. Hattinger CM, Fanelli M, Tavanti E, Vella S, Ferrari S, Picci P, Serra M. Advances in emerging drugs for osteosarcoma. Expert Opin Emerg Drugs. 2015;20(3):495-514.

5. Yang HW, Lu YJ, Lin KJ, Hsu SC, Huang CY, She SH, Liu HL, Lin CW, Xiao MC, Wey SP, Chen PY, Yen TC, Wei KC, Ma CC. EGRF conjugated PEGylated nanographene oxide for targeted chemotherapy and photothermal therapy. Biomaterials. 2013;34(29):7204-14.

6. Visvader JE, Lindeman GJ. Cancer stem cells in solid tumours: accumulating evidence and unresolved questions. Nat Rev Cancer. 2008:8:755-68.

7. Wong YC, Kim S, Peng W, Krainc D. Regulation and function of mitochondria-lysosome membrane contact sites in cellular homeostasis. Trends Cell Biol. 2019;29(6):500-13.

8. Bock FJ, Tait SWG. Mitochondria as multifaceted regulators of cell death. Nat Rev Mol Cell Biol. 2020;21:85-100.

9. Momcilovic M, Jones A, Bailey ST, Waldmann CM, Li R, Lee JT, Abdelhady G, Gomez A, Holloway T, Schmid E, Stout D, Fishbein MC, Stiles L, Dabir DV, Dubinett SM, Christofk H, Shirihai O, Koehler CM, Sadeghi S, Shackelford DB. In vivo imaging of mitochondrial membrane potential in non-small-cell lung cancer. Nature. 2019;575:380-4.

10. Lu P, Bruno BJ, Rabenau M, Lim CS. Delivery of drugs and macromolecules to the mitochondria for cancer therapy. J Control Release. 2016;240:38-51.

11. Yuan P, Mao X, Wu X, Liew SS, Li L, Yao SQ. Mitochondria-targeting, intracellular delivery of native proteins using biodegradable silica nanoparticles. Angew Chem Int Ed Engl. 2019;131(23):7739-43.

12. Chen S, Lei Q, Qiu WX, Liu LH, Zheng DW, Fan JX, Rong L, Sun YX, Zhang $X Z$. Mitochondria-targeting "Nanoheater" for enhanced photothermal/ chemo-therapy. Biomaterials. 2017;117:92-104.

13. Qi T, Chen B, Wang Z, Du H, Liu D, Yin Q, Liu B, Zhang Q, Wang Y. A pHactivatable nanoparticle for dual-stage precisely mitochondria-targeted photodynamic anticancer therapy. Biomaterials. 2019;213:119219.

14. Yan S, Zeng X, Tang Y, Liu BF, Wang Y, Liu X. Activating antitumor immunity and antimetastatic effect through polydopamine-encapsulated core-shell upconversion nanoparticles. Adv Mater. 2019;31(46):e1905825.

15. Guo M, Mao H, Li Y, Zhu A, He H, Yang H, Wang Y, Tian X, Ge C, Peng Q, Wang $X$, Yang $X$, Chen $X$, Liu G, Chen $H$. Dual imaging-guided photothermal/photodynamic therapy using micelles. Biomaterials. 2014;35(16):4656-66.

16. Zhang L, Wang D, Yang K, Sheng D, Tan B, Wang Z, Ran H, Yi H, Zhong Y, Lin H, Chen Y. Mitochondria-targeted artificial "Nano-RBCs" for amplified synergistic cancer phototherapy by a single NIR irradiation. Adv Sci. 2018:5(8):1800049.

17. Agostinis P, Berg K, Cengel KA, Foster TH, Girotti AW, Gollnick SO, Hahn SM, Hamblin MR, Juzeniene A, Kessel D, Korbelik M, Moan J, Mroz P, Nowis D, Piette J, Wilson BC, Golab J. Photodynamic therapy of cancer: an update. CA Cancer J Clin. 2011;61(4):250-81.

18. Yang G, Xu L, Xu J, Zhang R, Song G, Chao Y, Feng L, Han F, Dong Z, Li B, Liu Z. Smart nanoreactors for pH-responsive tumor homing, mitochondria-targeting, and enhanced photodynamic-immunotherapy of cancer Nano Lett. 2018;18(4):2475-84.

19. Guo R, Peng H, Tian Y, Shen S, Yang W. Mitochondria-targeting magnetic composite nanoparticles for enhanced phototherapy of cancer. Small. 2016;12(33):4541-52

20. Pan GY, Jia HR, Zhu YX, Wang RH, Wu FG, Chen Z. Dual channel activatable cyanine dye for mitochondrial imaging and mitochondria-targeted cancer theranostics. ACS Biomater Sci Eng. 2017;3(12):3596-606.
21. Zhang X, Du J, Guo Z, Yu J, Gao Q, Yin W, Zhu S, Gu Z, Zhao Y. Efficient near infrared light triggered nitric oxide release nanocomposites for sensitizing mild photothermal therapy. Adv Sci. 2019;6(3):1801122.

22. Sheng Z, Hu D, Zheng M, Zhao P, Liu H, Gao D, Gong P, Gao G, Zhang P, Ma Y, Cai L. Smart human serum albumin-indocyanine green nanoparticles generated by programmed assembly for dual-modal imagingguided cancer synergistic phototherapy. ACS Nano. 2014;8(12):12310-22.

23. Wang S, Huang P, Nie L, Xing R, Liu D, Wang Z, Lin J, Chen S, Niu G, Lu G, Chen X. Single continuous wave laser induced photodynamic/ plasmonic photothermal therapy using photosensitizer-functionalized gold nanostars. Adv Mater. 2013;25(22):3055-61.

24. Kalluru P, Vankayala R, Chiang CS, Hwang KC. Photosensitization of singlet oxygen and in vivo photodynamic therapeutic effects mediated by PEGylated $\mathrm{W}_{18} \mathrm{O}_{49}$ nanowires. Angew Chem Int Ed Engl. 2013;125(47):12558-62.

25. Tan X, Luo S, Long L, Wang Y, Wang D, Fang S, Ouyang Q, Su Y, Cheng T, Shi C. Structure-guided design and synthesis of a mitochondria-targeting near-infrared fluorophore with multimodal therapeutic activities. Adv Mater. 2017;29(43):1704196.

26. Shan W, Chen R, Zhang Q, Zhao J, Chen B, Zhou X, Ye S, Bi S, Nie L, Ren L. Improved stable indocyanine green (ICG)-mediated cancer optotheranostics with naturalized hepatitis B core particles. Adv Mater. 2018;30(28):e1707567.

27. Portnoy E, Gurina M, Magdassi S, Eyal S. Evaluation of the near infrared compound indocyanine green as a probe substrate of p-glycoprotein. Mol Pharm. 2012;9(12):3595-601.

28. Zeng YP, Luo SL, Yang ZY, Huang JW, Li R. A folic acid conjugated polyethylenimine-modified PEGylated nanographene loaded photosensitizer: photodynamic therapy and toxicity studies in vitro and in vivo. J Mater Chem B. 2016;4(12):2190-8.

29. Zeng YP, Yang ZY, Luo SL, Li H, Liu C, Hao YH, Liu J, Wang WD, Li R. Fast and facile preparation of PEGylated graphene from graphene oxide by lysosome targeting delivery of photosensitizer to efficiently enhance photodynamic therapy. RSC Adv. 2015;5(71):57725-34.

30. Zeng YP, Yang ZY, Li H, Hao YH, Liu C, Zhu L, Liu J, Lu BH, Li R. Multifunctional nanographene oxide for targeted gene-mediated thermochemotherapy of drug-resistant tumour. Sci Rep. 2017;7:43506.

31. Luo SL, Yang ZY, Tan X, Wang Y, Zeng YP, Wang Y, Li C, Li R, Shi CM. Multifunctional photosensitizer grafted on polyethylene glycol and polyethylenimine dual-functionalized nanographene oxide for cancertargeted near-infrared imaging and synergistic phototherapy. ACS Appl Mater Interfaces. 2016;8(27):17176-86.

32. Feng $L$, Yang $X$, Shi X, Tan X, Peng R, Wang J, Liu Z. Polyethylene glycol and polyethylenimine dual-functionalized nano-graphene oxide for photothermally enhanced gene delivery. Small. 2013;9(11):1989-97.

33. Zhang W, Guo Z, Huang D, Liu Z, Guo X, Zhong H. Synergistic effect of chemo-photothermal therapy using PEGylated graphene oxide. Biomaterials. 2011;32(33):8555-61.

34. Yang K, Wan J, Zhang S, Zhang Y, Lee ST, Liu Z. In vivo pharmacokinetics, long-term biodistribution, and toxicology of PEGylated graphene in mice. ACS Nano. 2011:5(1):516-22.

35. Zhao R, Kong W, Sun M, Yang Y, Liu W, Lv M, Song S, Wang L, Song H, Hao R. Highly stable graphene-based nanocomposite (GO-PEI-Ag) with broad-spectrum, long-term antimicrobial activity and antibiofilm effects. ACS Appl Mater Interfaces. 2018;10(21):17617-29.

36. Logan A, Pell VR, Shaffer KJ, Evans C, Stanley NJ, Robb EL, Prime TA, Chouchani ET, Cocheme HM, Fearnley IM, Vidoni S, James AM, Porteous CM, Partridge L, Krieg T, Smith RA, Murphy MP. Assessing the mitochondrial membrane potential in cells and in vivo using targeted click chemistry and mass spectrometry. Cell Metab. 2016;23(2):379-85.

37. Marcano DC, Kosynkin DV, Berlin JM, Sinitskii A, Sun Z, Slesarev A, Alemany LB, Lu W, Tour JM. Improved synthesis of graphene oxide. ACS Nano. 2010;4(8):4806-14

38. Zhang C, Liu T, Su Y, Luo S, Zhu Y, Tan X, Fan S, Zhang L, Zhou Y, Cheng $\mathrm{T}$, Shi C. A near-infrared fluorescent heptamethine indocyanine dye with preferential tumor accumulation for in vivo imaging. Biomaterials. 2010;31(25):6612-7.

39. Feng C, Huang X. Polymer brushes: efficient synthesis and applications. Acc Chem Res. 2018;51(9):2314-23. 
40. Xu Z, Wang S, Li Y, Wang M, Shi P, Huang X. Covalent functionalization of graphene oxide with biocompatible poly (ethylene glycol) for delivery of paclitaxel. ACS Appl Mater Interfaces. 2014;6(19):17268-76.

41. Xu Z, Zhu S, Wang M, Li Y, Shi P, Huang X. Delivery of paclitaxel using PEGylated graphene oxide as a nanocarrier. ACS Appl Mater Interfaces. 2015;7(2):1355-63.

42. Li Y, Jian Z, Lang M, Zhang C, Huang X. Covalently functionalized graphene by radical polymers for graphene-based high-performance cathode materials. ACS Appl Mater Interfaces. 2016:8(27):17352-9.

43. Que Y, Feng C, Lu G, Huang X. Polymer-coated ultrastable and biofunctionalizable lanthanide nanoparticle. ACS Appl Mater Interfaces. 2017;9(17):14647-55.

44. Wang Z, Jia T, Sun Q, Kuang Y, Liu B, Xu M, Zhu H, He F, Gai S, Yang P. Construction of $\mathrm{Bi} /$ phthalocyanine manganese nanocomposite for trimodal imaging directed photodynamic and photothermal therapy mediated by 808 nm light. Biomaterials. 2020;228:119569.

45. Tee JK, Yip LX, Tan ES, Santitewagun S, Prasath A, Ke PC, Ho HK, Leong DT. Nanoparticles' interactions with vasculature in diseases. Chem Soc Rev. 2019;48:5381-407.

46. Ye S, Rao J, Qiu S, Zhao J, He H, Yan Z, Yang T, Deng Y, Ke H, Yang H, Zhao Y, Guo Z, Chen H. Rational design of conjugated photosensitizers with controllable photoconversion for dually cooperative phototherapy. Adv Mater. 2018;30(29):e1801216.

47. Aranda A, Sequedo L, Tolosa L, Quintás G, Gombau L. Dichloro-dihydrofluorescein diacetate (DCFH-DA) assay: a quantitative method for oxidative stress assessment of nanoparticle-treated cells. Toxicol In Vitro. 2013;27(2):954-63.

48. Zhang BB, Wang DG, Guo FF, Xuan C. Mitochondrial membrane potential and reactive oxygen species in cancer stem cells. Fam Cancer. 2015;14:19-23.

49. Yu M, Shi Y, Wei X, Yang Y, Zhou Y, Hao X, Zhang N, Niu R. Depletion of mitochondrial DNA by ethidium bromide treatment inhibits the proliferation and tumorigenesis of T47D human breast cancer cells. Toxicol Lett. 2007;170(1):83-93.

50. Zorova LD, Popkov VA, Plotnikov EY, Silachev DN, Pevzner IB, Jankauskas SS, Babenko VA, Zorov SD, Balakireva AV, Juhaszova M, Sollott SJ, Zorov DB. Mitochondrial membrane potential. Anal Biochem. 2018;552(1):50-9.

51. Han K, Zhu JY, Jia HZ, Wang SB, Li SY, Zhang XZ, Han HY. Mitochondriatargeted chimeric peptide for trinitarian overcoming of drug resistance. ACS Appl Mater Interfaces. 2016;8(38):25060-8.

52. Sherratt HS, Turnbull DM. Mitochondrial oxidations and ATP synthesis in muscle. Baillieres Clin Endocrinol Metab. 1990;4(3):523-60.

\section{Publisher's Note}

Springer Nature remains neutral with regard to jurisdictional claims in published maps and institutional affiliations.
Ready to submit your research? Choose BMC and benefit from:

- fast, convenient online submission

- thorough peer review by experienced researchers in your field

- rapid publication on acceptance

- support for research data, including large and complex data types

- gold Open Access which fosters wider collaboration and increased citations

- maximum visibility for your research: over $100 \mathrm{M}$ website views per year

At BMC, research is always in progress.

Learn more biomedcentral.com/submissions 